University of Northern Colorado

Scholarship \& Creative Works @ Digital UNC

Dissertations

Student Research

$12-1-2011$

\title{
Preservice teachers' self efficacy and knowledge of emotional and behavioral disorders
}

Shani Shillingford

Follow this and additional works at: http://digscholarship.unco.edu/dissertations

\section{Recommended Citation}

Shillingford, Shani, "Preservice teachers' self efficacy and knowledge of emotional and behavioral disorders" (2011). Dissertations. Paper 254. 


\title{
UNIVERSITY OF NORTHERN COLORADO
}

\author{
Greeley, Colorado
}

The Graduate School

\section{PRESERVICE TEACHERS' SELF EFFICACY AND KNOWLEDGE OF EMOTIONAL AND BEHAVIORAL DISORDERS}

\author{
A Dissertation Submitted in Partial Fulfillment \\ of the Requirements for the Degree of \\ Doctor of Philosophy
}

\author{
Shani Shillingford \\ College of Education and Behavioral Sciences \\ School of Psychological Sciences \\ Educational Psychology
}

December, 2011 


\begin{abstract}
Shillingford, Shani. Preservice Teachers Self Efficacy and Knowledge of Emotional and Behavioral Disorders. Published Doctor of Philosophy dissertation, University of Northern Colorado, (2011).
\end{abstract}

The extent of preservice teachers' knowledge of emotional and behavioral disorders (EBD) and their self efficacy were examined in this research. The participants included a convenience sample of 230 (184 females, 46 males) undergraduate general education and special education preservice teachers enrolled in Fall 2011 teacher education classes in a mid-sized Midwestern university, located in a mid-sized city. The age of the participants ranged from 19 to 51 with a mean age of 23.37 years $(S D=6.8$ years). The Teacher Self Efficacy Scale (TSES) (long form) and Knowledge of Emotional and Behavioral Disorders questionnaire were administered to the sample.

The participants had an overall high sense of efficacy but had higher efficacy in instructional strategies than in classroom management, student engagement, and instructional abilities. Participants demonstrated some knowledge of EBD. There was no significant association between field experience, additional coursework, and familiarity with a child with EBD and the preservice teachers' knowledge of EBD or self efficacy. It is recommended that teacher education program coordinators place more emphasis on providing teacher candidates with information regarding successfully identifying, engaging, and motivating students with EBD. 
Additionally, preservice teachers' field experiences should include more authentic experiences with students with EBD to enhance preservice teachers' self efficacy for successfully working with students with EBD in their diverse classrooms. 


\section{TABLE OF CONTENTS}

CHAPTER I- INTRODUCTION 1

$\begin{array}{ll}\text { Definition of Terms } & 12\end{array}$

$\begin{array}{ll}\text { Purpose of the Study } & 13\end{array}$

$\begin{array}{ll}\text { Research Questions } & 14\end{array}$

$\begin{array}{ll}\text { Significance of the Study } & 14\end{array}$

$\begin{array}{ll}\text { Limitations } & 15\end{array}$

$\begin{array}{ll}\text { Overview } & 15\end{array}$

CHAPTER II -LITERATURE REVIEW 16

$\begin{array}{ll}\text { Teachers' Self Efficacy } & 16\end{array}$

$\begin{array}{lr}\text { Self efficacy in Academic Context } & 18\end{array}$

Factors that affect Teachers' Self Efficacy 20

$\begin{array}{ll}\text { Efficacy in Specific Teaching Contexts } & 23\end{array}$

The Influence of Collective Efficacy on Self Efficacy 26

$\begin{array}{ll}\text { Efficacy and Burnout } & 28\end{array}$

Self Efficacy and the Teacher-Student Relationship 31

$\begin{array}{ll}\text { Summary } & 34\end{array}$

CHAPTER III- METHODOLOGY 35

Sample Selection $\quad 35$

$\begin{array}{ll}\text { Instruments } & 37\end{array}$ 
Procedures

Data Analysis $\quad 45$

$\begin{array}{ll}\text { Summary } & 51\end{array}$

CHAPTER IV- RESULTS

$\begin{array}{ll}\text { Participants } & 53\end{array}$

Scores on the Knowledge of EBD Questionnaire 56

Scores on the Teacher Self Efficacy Scale $\quad 57$

Results of Inferential Statistical Analysis $\quad 61$

Answers to Research Questions 64

$\begin{array}{ll}\text { Summary } & 68\end{array}$

$\begin{array}{ll}\text { CHAPTER V-DISCUSSION } & 70\end{array}$

$\begin{array}{ll}\text { Summary of the Purpose of the Study } & 70\end{array}$

$\begin{array}{ll}\text { Discussion of the Findings } & 71\end{array}$

$\begin{array}{ll}\text { Conclusion } & 79\end{array}$

$\begin{array}{ll}\text { Limitations } & 81\end{array}$

$\begin{array}{lr}\text { Future Research } & 82\end{array}$

$\begin{array}{lr}\text { Summary } & 82\end{array}$

$\begin{array}{lr}\text { REFERENCES } & 84\end{array}$

APPENDICES

$\begin{array}{ll}\text { APPENDIX A- CONSENT FORM } & 95\end{array}$

APPENDIX B- KNOWLEDGE OF EBD QUESTIONNAIRE 97

APPENDIX C - DEMOGRAPHIC INFORMATION QUESTIONNAIRE 100 
APPENDIX E- INSTUTIONAL REVIEW BOARD APPLICATION 


\section{LIST OF TABLES}

1. Factor Loadings for Exploratory Factor Analysis for the TSES

2. TSES Subscale Distribution and Reliability

3. Demographic Table

4. Educational Statistics

5. Group distributions

6. Contrast tables on the TSES Subscales

7. Multivariate Tests

8. ANOVA Table 


\section{LIST OF FIGURES}

1. Scree Plot for Knowledge of EBD items 49

2. Total Knowledge Scores $\quad 57$

3. Efficacy in Instructional Strategies Subscale 58

4. Efficacy in Classroom Management Subscale 59

5. Efficacy in Student Engagement Subscale 60

6. Efficacy in Instructional Ability Subscale 61 


\section{CHAPTER I}

\section{INTRODUCTION}

Prior to the establishment of the Individual with Disabilities Education Act (IDEA) in 1975, students with disabilities in the United States were denied access to proper education. The IDEA placed into law provisions for the appropriate education of children with disabilities. The IDEA states that children and youth age 3-21 with disabilities are mandated to receive free and appropriate public education. After the passing of the No Child Left Behind Act of 2001 (NCLB), which sought to ensure each state provided students with the opportunity to meet their educational goals, the IDEA was amended in 2004 to further ensure that students with disabilities received the services needed for a proper education based on the state's definition of the "adequate yearly progress" (U.S. Department of Education, 2010).

Through the passing of the IDEA, inclusion has been considered as the best approach for educating students with disabilities. Inclusion is defined as "the instructional and social integration of students with disabilities with non-disabled peers to the maximum extent possible in a neighborhood school placement" (D'Alonzo, Giordano, \& Cross, 1996, p. 307). The concept of inclusion suggests that the child will greatly benefit from socializing with and learning from other students in the general education classroom. These benefits are considered more substantive than the benefits 
to be derived from placement in restrictive environments despite the child's special needs. The general concept behind inclusion is that all children can be educated with good instruction in a properly managed general education classroom (Newcomer, 2003).

According to the 2007 National Center for Education Statistics (NCES) data, 95\% of students with disabilities were served in regular schools. Thirteen percent of the student population received special education services which numbered to 6.6 million children and youth. Seven percent of these students were diagnosed with emotional disturbances (NCES, 2010). Thus, the management and education of students with emotional and behavioral disorders (EBD) is not only the responsibility of special education teachers, general education teachers are also faced with the task of providing an educational program that meets the academic, social, and behavioral needs of students with EBD (Lane, Wehby, \& Barton-Arwood 2005).

Jobe, Rust, and Brissie (1996) explored teachers opinions about inclusion and found teachers were more willing to accommodate children with physical disabilities compared to children with cognitive, emotional and behavioral problems. Teachers believed that inclusion would be beneficial to some students. Also, teachers who had previous experience in inclusive classrooms expressed more positive attitudes towards inclusion. Similarly, Lanier and Lanier (1996) carried out a longitudinal study with teachers immediately after completion of a required course and then after completion of 5 years of full time teaching to explore teachers' attitudes towards students with disabilities. Teachers were presented with various scenarios describing students with different disabilities and asked to rate their comfort level for having the students depicted in the scenarios in their classrooms. There was minimal change in teachers' ratings between administrations. The teachers rated the students with profound and severe 
disabilities as the ones least appropriate for inclusion in general classrooms. Though teachers were willing to include a wide range of challenged students those with potentially distracting disabilities were the ones considered least acceptable for inclusion. The results of this survey indicate that teachers continue to have mixed feelings about inclusion and the students they would be comfortable working with in their classrooms. In a similar study, Cook (2001) reviewed teachers' attitudes about inclusion of students with hidden disorders such as Attention Deficit Hyperactivity Disorders (ADHD), behavioral disorders, and learning disabilities, and visible disorders such as autism and mental retardation. Teachers more readily reported rejection of students with hidden disorders since these disorders pose more classroom management problems. Cook concluded that teachers form different attitudes and expectations about including students with disabilities in their classrooms depending on the severity or obviousness of the disability.

Consequently, it is important for teachers to be fully equipped to work with students with emotional and behavioral disorders. Children who are diagnosed with emotional or behavioral disorders are most likely to be suspended from school, commit crimes, or become institutionalized. These students experience low academic progress and may drop out of school (Kauffman, 1997). Also, teachers' response to students with EBD plays an important role in curbing students' behavior since negative reactions from teachers can increase students' non-productive behaviors. This negative reaction also leads to a breakdown in the student-teacher relationship and leads to the student's detachment from school (Cooper, 2006). Hence, as suggested by Furlong, Morrison, and 
Jimerson (2004), a teacher should be skilled in handling misbehavior and should be able to encourage positive behaviors from students in an effort to curb negative behaviors in the classroom.

\section{Teacher Attrition}

The NCES report on projections for 2019 indicated that the total number of elementary and secondary teachers increased by $24 \%$ between 1994 and 2007 and is projected to increase an additional $13 \%$ between 2007 and 2019. The number of new teachers in public schools was approximately 246,000 in 2007 and is expected to increase by $40 \%$ to 344,000 in 2019 . The new teachers hired in private schools were approximately 80, 000 in 2007 with a projected increase of $19 \%$ to 96,000 in 2019 (NCES, 2010). These statistics demonstrate the growing trend of novice teachers in classrooms, and the importance of ensuring that these teachers are properly equipped to work in diverse classrooms. Additionally, it is important to ensure new teachers are fully prepared for the stress of the classroom in order to decrease attrition rates.

There is a growing trend of teachers, especially new teachers, leaving the profession. NCES (2010) data indicated that of the 3,380,300 public school teachers who were teaching during the 2007-08 school year, $84.5 \%$ remained at the same school, 7.6 $\%$ moved to a different school and $8.0 \%$ left the profession during the following year. Among the 487,300 private school teachers who were teaching during the 2007-08 school year, $79.2 \%$ stayed at the same school, $4.9 \%$ moved to a different school, and $15.9 \%$ left the profession. Furthermore, among public school teachers with 1-3 years of experience, $77.3 \%$ stayed in the same school, $13.7 \%$ moved to another school, and $9.1 \%$ left teaching in 2008-09. 
There are various factors that contribute to teachers' attrition rates. The rate of attrition differs based on the type of teacher and subjects taught. It is observed that special education teachers have higher attrition rates than general education teachers. Also, math, science, and unqualified teachers are at greatest risk for attrition (Billingsley, 2004). Moreover, the risk factors identified for new teachers include typical stressors in first year of teaching, expectations and scope of the job, lack of support, and the gap between visions of teaching and the realities of the job. It is believed that personal efficacy and emotional competence along with the novice teachers' resilience may be important in helping beginning teachers become more confident and committed to teaching and thus increase retention rates (Taitt, 2008).

Billingsley and Cross (1992), in an effort to identify the factors that influence retention, surveyed special education and general education teachers. The study showed that leadership support, work involvement, and lower levels of role conflict and stress were predictors of commitment and job satisfaction for both general and special education teachers. Also, professional commitment was positively related to job involvement and negatively correlated with stress. Furthermore, general education teachers reported higher levels of stress than did special education teachers. Stress and burnout among special education teachers were related to high levels of conflict and ambiguity in their responsibilities.

Similar results were found in Sing and Billingsley's (1996) survey of teachers working with students with emotional disorders. Participants revealed elevated levels of stress, which lowered job satisfaction and job commitment. A supportive work environment, professional commitment, and years of teaching experience influenced teachers' willingness to stay in the profession. Similarly, Billingsley (2004) studied 
special education teachers and discovered that the work environment, lack of administrative support, and stress were related to attrition rates. Whereas, increased job satisfaction, supportive mentors, and a positive school climate influenced special education teachers' willingness to stay. Further, special education teachers working with students with learning disabilities, physical disabilities, and mental retardation were more likely to stay in the profession than were special education teachers who worked with students with emotional problems.

\section{Emotional and Behavioral Disorders}

Students who are diagnosed with emotional and behavioral disorders are more likely to receive lower grades, make less academic progress, and receive more disciplinary actions than are other students with disabilities. Those students who are considered by the school to be socially maladjusted are more likely to be on the school's list for suspension or expulsion (Bradley, Henderson, \& Monfore, 2004; Furlong et al., 2004). Students with EBD are seen as having poor self concept, mood swings, and poor self control. They are considered explosive, disruptive, dangerous, rebellious, and dropouts (Rizza \& Morrison, 2003).

Those students who are diagnosed with EBD are not only at risk for suspension from school, but they may commit crimes or become institutionalized (Kauffman, 1997). The attention or hyperactivity problems that manifest during elementary school continue to have an impact on the students' peer relations and academic performance throughout the school career. These behaviors may also influence the student's social relations and 
may affect relations with peers and others in the community. Hence, it is important to appropriately diagnose and intervene at an early stage in order to decrease the negative effects of the disorder (Furlong, et al., 2004).

Emotional and behavioral disorders fall under two broad categories, externalizing and internalizing behaviors. Externalizing behaviors are categorized by aggression and acting out, whereas internalizing behaviors involve social withdrawal. Children displaying externalizing behaviors are most commonly diagnosed with Attention Deficit Hyperactivity Disorder (ADHD) and conduct disorders (Furlong, et al., 2004; Kauffman, 1997). Internalizing behaviors usually lead to diagnoses of depression, anxiety, social withdrawal, obsessive compulsive disorders, or selective mutism (Gresham \& Kern, 2004). It is important to recognize that emotional and behavioral disorders are difficult to diagnose and may coexist with other disorders such as schizophrenia. This has made it difficult to formulate a definition that encompasses all aspects of the disorder (Kauffman, 1997).

In an effort to establish a definition of EBD to be widely used in all circles the IDEA in joint collaboration with the National Mental Health and Special Education Coalition utilizes the definition:

- Emotional or Behavioral Disorder (EBD) refers to a condition in which behavioral or emotional responses of an individual in school are so different from his/her generally accepted, age appropriate, ethnic or cultural norms that they adversely affect performance in such areas as self care, social relationships, personal adjustment, academic progress, classroom behavior, or work adjustment.

- EBD is more than a transient, expected response to stressors in the child's or youth's environment and would persist even with individualized interventions, such as feedback to the individual, consultation with parents or families, and/or modification of the educational environment. 
- The identification of EBD must be based on multiple sources of data about the individual's behavioral or emotional functioning. EBD must be exhibited in at least two different settings, at least one of which is school related.

- EBD can co-exist with other disabilities. This category may include children or youth with schizophrenia, affective disorders, anxiety disorders, or who have other sustained disturbances of behavior, emotions, attention, or adjustment. The impact of the behavior on the student's educational progress must be the guiding principle for identification (National Association of School Psychologists, 2005, para. 2).

Externalizing behaviors are more overt and thus students who display these behaviors are more often referred because these behaviors are more likely to disrupt the class and undermine the teacher's authority. These behaviors are the least tolerated in the classroom and regularly lead to the referral of students (Gresham \& Kern, 2004). Hence, the skills of the teacher to handle the student's misbehavior are important for fostering positive behaviors. Students with EBD are least likely to be called on for classroom discussions and receive less positive feedback for providing correct responses. Also, a teacher who has no strategies for working with a child with EBD and gives the child negative attention puts the student more at risk for school failure (Furlong et al., 2004).

Students displaying internalizing behaviors are also at risk for poor academic performance and need positive interactions with teachers. Students with diagnoses such as anxiety, depression, and withdrawal also do poorly in classroom performance, since they are least likely to partake in classroom activities and are at risk for poor performance on achievement tests (Rapport, Denney, Chung, \& Hustace, 2001). Internalizing behaviors often go unnoticed by others because of their subtle nature. Hence, internalizing behaviors pose a problem for diagnosis, assessment, and intervention in schools, resulting in under-referral of students displaying internalizing behaviors (Gresham \& Kern, 2004). 
The problem of adequate referral was investigated in a study by Soles, Bloom, Heath, and Karagiannakis (2008). Teachers were asked to rate students as displaying symptoms of EBD. Teachers' ratings were compared against students' ratings of themselves. The teachers rated significantly more boys than girls, with the highest rating being for externalizing behaviors. Girls who were rated with externalizing behaviors were considered to have more severe problems than boys. This finding indicates that girls' problems have to be considered extreme to be considered for referral. Additionally, there was little overlap between the students teachers rated as having internalizing problems and the students' ratings. These differences indicate the difficulties teachers face in adequately identifying students' internal problems and the over- emphasis on the display of externalizing behaviors as a requirement for referral.

\section{Teachers' Attitudes about Students with Disabilities}

Monahan, Marino, and Miller's (1996) survey of regular teachers revealed that teachers thought that inclusion would not work because of the general education teachers' resistance. Also, it was believed that general education teachers lack the instructional skills and educational background to teach students with special needs. D'Alonzo et al. (1996) recognized that general education teachers have little or no preparation in educating students with disabilities. They often leave the education of students with disabilities to those teachers who are trained to do so. Additionally, many general education teachers have a negative attitude about students with disabilities and the inclusion of these students in their classrooms. 
There are various factors that contribute to general education teachers' attitude about students with disabilities and the inclusion of these students in their classrooms. These factors include teachers' age, level of education, years spent in teaching, experience working with a child with disability, knowledge about disabilities, preservice and inservice training, grade level taught, availability of resources, administrative support, and teachers' confidence in their teaching skills (D'Alonzo et al., 1996; Jeon \& Peterson, 2003).

However, teachers' attitudes about students with disabilities can be modified by providing teachers with information about disabilities, through direct contact or exposure to persons with disabilities, or through vicarious experiences (D’Alonzo et al., 1996). Jeon and Peterson's (2003) study of preservice teacher attitudes found that teachers who had experience working with students with disabilities did not necessarily have favorable attitudes towards inclusion. However, those teachers who had a personal relationship with persons with disabilities were more likely to have a positive attitude towards inclusion. Similarly, those who had previous relevant coursework were more likely to have a positive attitude. Additionally, those teachers who would be working with students from birth to eight years tend to have a more favorable attitude towards inclusion that those in the elementary education program.

This difference in teachers' attitudes based on grade levels taught is similar to Larrivee and Cook's (1979) study which found that teachers' attitudes become increasingly less positive as grade levels taught increased. Kindergarten teachers were seen to have a more positive attitude about inclusion and junior high school teachers had 
a more negative attitude. Additionally, the availability of administrative support and support staff helped increase teachers' positive attitudes towards inclusion. There were no differences in teachers' attitudes across urban, rural, or suburban schools.

Moreover, Shippen, Crites, Houchins, Ramsey, and Simon (2005) found that future special education teachers are more receptive to the idea of inclusion than are future general education teachers. General education teachers had more anxiety about inclusion but enrollment in a course about special education eased this anxiety. Hence, a combination of field experience and coursework may greatly reduce teacher candidates' anxiety about inclusion. Turner (1995) suggested that preservice teachers must be immersed in experiences that not only increase knowledge but change attitudes about creating environments conducive for teaching students with disabilities.

Similarly, Kamen, Loprete, and Slostad (2000) observed that teachers believed that teacher preparation programs should focus on strategies and approaches for including students with disabilities in the classrooms. These could either be through the provision of courses focused on integration and strategies or incorporating these into already existing coursework.

However, Mock and Kauffman (2002) argued there is no way to fully equip general education teachers to work in the inclusive classroom. Teachers are expected to teach each variety of students in a fair and just manner and this is not possible given the variability in teacher preparation. Some teachers may have extensive coursework in special education and others may have minimal knowledge. In an effort to address this concern, the Council for Exceptional Children established a list of the minimum knowledge, skills, and dispositions needed by special education teachers for effectively 
working with students with EBD. Many teacher preparation programs have begun using this list as part of coursework; however, these programs are finding it difficult to incorporate all items on the list in coursework (Manning, Bullock, \& Gable, 2009). Accordingly, Yost (2006) found that teachers indicated that their numerous and varied student teaching field experiences, especially experience connected to context, increased their confidence in using and developing various teaching and management strategies. Also, experiences of failure while student teaching or early in their career determined how long teachers endured and remained in the profession. Elliot, Issac, and Chugani_(2010) recognized that early career teachers who do not have a sense of efficacy for teaching due to a lack of prior experiences, preparation, or other factors may be likely to leave the profession within the first few years. Skills and abilities are likely to be developed throughout a teacher's career; hence, teachers' skills and abilities must be fostered after education is completed and teachers are in the classroom. Elliot et al. recommended that early career teachers should be provided with support and supervision and should be matched with reliable mentors.

\section{Definition of Terms}

Authentic experiences are learning experiences in which the preservice teacher is engaged in the learning process. The content is made relevant to the students' experiences and thus they are better able to construct new knowledge and make meanings from the subject content (Gurvitch \& Metzler, 2008).

Burnout is described as a delayed reaction to the emotional and interpersonal stressors encountered on the job. Burnout is characterized by exhaustion, detachment from the job, feelings of pessimism and ineffectiveness, and lack of accomplishment (Maslach, Schaufeli, \& Leiter, 2001). 
Collective efficacy is the belief in combined competence shared among the individuals of the group when organizing their resources in a concerted effort to meet the demands of their current situation (Zaccaro, Blair, Peterson, \& Zazanis, 1995).

Emotional and Behavioral Disorder $(E B D)$ refers to a condition in which the behavioral and emotional responses of a student in school are different from the generally accepted, age appropriate, ethnic or cultural norms. This condition affects the students' academic performance, social relationships, self care, and classroom behavior (National Association of School Psychologists, 2005).

Inclusion is defined as the social and instructional integration of students with disabilities and those with non- disabilities within the same classroom (D'Alonzo et al., 1996). It is believed that all students can learn with good instruction in a well managed general education classroom (Newcomer, 2003).

Teachers' self efficacy is a teacher's belief in their ability and skill to influence student learning despite the external factors (Ashton \& Webb, 1986).

\section{Purpose of the Study}

There is a lack of research directed at preservice teachers' knowledge of emotional and behavioral disorders and how it influences teachers' self efficacy. Most of the research on preservice teachers focuses on their ability to manage students with EBD (Soles et al., 2008; Sutherland, Lewis-Palmer, Stichter, \& Morgan, 2008). However, it is important to examine preservice teachers' knowledge of EBD as this will increase the early identification of students with EBD and lead to adequate interventions that will not only benefit the students but the teachers themselves. Students who are identified as 
having EBD and are properly managed are less likely to disrupt the classroom and thus lead to teachers' effective management of their diverse classrooms, reduction in teachers' stress levels, and increases in their commitment to the job (Gresham \& Kern, 2004).

Accordingly, this research answered the following research questions:

Q1 To what extent does personal experience, field experience, coursework, and knowledge of EBD predict preservice teachers' self efficacy? (Main \& Hammond, 2008) (Knowledge of EBD questionnaire and TSES)

Q2 Are there any differences among special education and general education teacher programs with regards to knowledge of emotional and behavioral disorders? (Manning et al., 2009) (Knowledge of EBD questionnaire)

Q3 Are there any differences in preservice teachers' knowledge of EBD and self efficacy across the different teacher education programs? (Billingsley, 2004) (Knowledge of EBD questionnaire and TSES)

Q4 Does practicum experience and exposure to a student diagnosed with EBD during the practicum experience influence preservice teachers' efficacy in student engagement? (D’Alonzo et al., 1996) (TSES-Efficacy in Student Engagement subscale)

\section{Significance of the Study}

The current research will be useful to teacher education program coordinators to assist in further developing effective programs that equip new teachers with the tools needed for working with diverse populations, enhance preservice teachers' self efficacy, and thus assist in decreasing the attrition rates of new teachers. Accordingly, this research will help teacher education program coordinators develop new strategies for providing teacher candidates with authentic field experiences that will further increase preservice teachers' self efficacy in working with students diagnosed with emotional and behavioral disorders. 


\section{Limitations}

This research is limited by the sample utilized. Participants in the study are made up of a convenience sample of preservice teachers from one Midwestern university. Thus, the results of the study will be restricted to one university and the nature of the teacher education programs in this university. Furthermore, this research used quantitative methods and thus may fail to adequately capture the preservice teachers' experiences in their teacher preparation programs.

\section{Overview}

This study is divided into five chapters. Chapter I introduced the problem to be investigated, the purpose and significance of the study, the research questions to be answered, and the limitations of the study. Chapter II reviews the relevant literature related to teachers' self efficacy and its influence on teachers' attitudes about working with students with emotional and behavioral disorders. The relevant theories and literature which directed this study are also outlined. Chapter III provides information on the process of selecting a sample for the study, the instruments used, and the procedures for administering the instruments. Chapter IV and V presents the results of the study, discusses the findings and limitations of the study, and suggests areas for further research. 


\section{CHAPTER II}

\section{LITERATURE REVIEW}

This chapter will focus on teachers' self efficacy by providing a definition of self efficacy and an explanation of its relationship to the academic context. Teachers' self efficacy is relevant in teachers' willingness to work with students with emotional and behavioral disorders, and determines the amount of effort a teacher would put forth in providing a classroom environment suitable for learning. This chapter also explains the factors that affect teachers' self efficacy and how self efficacy is manifested in specific contexts. The links between self efficacy and collective efficacy, and self efficacy and burnout in teachers will also be explored. Additionally, self efficacy is important for fostering positive teacher-student relationships, and the relevance of these relationships will be presented in this chapter.

\section{Teachers' Self Efficacy}

Self efficacy is defined as one's belief in his or her ability to partake in the actions required to successfully accomplish a specific task in a specific context (Bandura, 1986). Teacher self efficacy is important for creating environments conducive for learning, as those with high efficacy will put in more effort into their instructional strategies. Similarly, teachers who have low efficacy try to avoid dealing with academic problems by turning their effort inwards to relieve their emotional distress and this leads to burnout (Bandura, 1993). 
Additionally, teachers' self efficacy plays an essential role in teachers' willingness to include students with EBD in their classrooms (Main \& Hammond, 2008). Moreover, teachers' self efficacy is important in helping teachers cope with the stress of the job and thereby decrease the attrition rates of teachers (Bandura, 1993).

Thus, it is important for teachers of students with EBD to have a high sense of efficacy, in order to successfully meet these students' needs in a general education classroom. The ability of a teacher to create an environment favorable for learning is dependent on the teacher's talents and self efficacy. A teacher who has a strong sense of efficacy in the classroom builds an environment that supports the development of students' intrinsic needs and helps students to achieve their academic goals (Bandura, 1993).

An individual's sense of efficacy serves as the determinant of a person's behavior, thought patterns, and emotional reactions to the difficult situations they encounter. Self efficacy also determines how much energy a person will utilize and their persistence in the face of obstacles or aversive situations. Those with low self efficacy will put forth a relaxed performance or give up altogether on a challenging task, whereas those with high self efficacy will continue to persevere to master the challenges (Bandura, 1982). Hence, individuals' poor performance in situations may be a result of their lack of perceived self efficacy to make optimal use of their skills or ability. Subsequently, if a person's belief in their ability to cope is strengthened by obtaining additional knowledge and skills; they can approach situations more confidently and make better use of their skills and abilities (Bandura, 1992). 
Bandura (1986) proposed that judgments of self efficacy are based on four main sources of information: performance attainment, vicarious experiences of observing the performance of others, verbal persuasion, and physiological states on which individuals base their capabilities, strengths, and vulnerabilities:

- Performance attainment is the most influential since it relates to mastery experiences. Success increases efficacy and failure decreases efficacy.

- Vicarious experiences- seeing others of similar ability perform successfully, influences efficacy because one believes they in turn can conquer similar circumstances. Inversely, seeing others fail decreases one's belief in their capabilities.

- Verbal persuasion is used to get people to believe they possess the capabilities needed to succeed at a task.

- Physiological states- because high arousal decreases performance, people gauge their success based on their arousal in the circumstances. In activities involving strength and stamina, signs of fatigue, aches, and pain indicate physical inefficacy (p. 399).

\section{Self Efficacy in Academic Context}

A teacher's sense of efficacy is the belief that the teacher has the abilities and skills to influence student learning. Additionally, a teacher's sense of efficacy is determined by the teacher's belief that the ability to bring about change is limited by external factors such as the student's home environment, family background, and parental influences (Dembo \& Gibson, 1985). Moreover, Ashton and Webb (1986) indicated that teachers' sense of efficacy refers to teachers' belief that they can help students learn despite the situation. Teachers with a low sense of efficacy doubt their ability to influence student learning, and they tend to reduce their efforts or give up entirely when faced with difficulties. 
Ashton and Webb (1986) indicated that teachers' sense of efficacy consists of two factors, sense of teaching efficacy and sense of personal teaching efficacy. Sense of teaching efficacy refers to the teachers' beliefs that their teaching can be influential in helping students to learn; while sense of personal efficacy refers to the teachers' beliefs in their competence as a teacher. A teacher with high efficacy believes that all students are capable of learning. Whereas, a teacher with a low sense of teaching efficacy believes that some students can or will not learn in school and there is nothing a teacher can do to change this outcome. Additionally, Ashton and Webb recognized that a teacher's sense of personal efficacy influences the teacher's choice of classroom management and instructional strategies. A teacher who has low efficacy in his or her classroom management skills may avoid situations in which he or she doubts a personal capability for controlling students and allowing them to ignore the rules. Consequently, teachers who doubt their abilities in the classroom will experience increased stress levels.

A teacher's sense of efficacy affects their willingness to help students and the effort they will expend especially when working with low-achieving or difficult students. Ashton and Webb (1986) found that low efficacy teachers were more likely to claim that low-achieving students did not learn because the students are incapable of learning. As such, the teachers are unable to increase the students' achievement. However, high efficacy teachers were found to demonstrate pride in helping low achieving students to learn. Bandura (1997) indicated that teachers who have a low efficacy in instructional strategies have a low commitment to teaching and are more at risk for burnout.

Furthermore, Dembo and Gibson (1985) suggested that teachers develop feelings of inadequacy when they recognize they lack the necessary knowledge and skills to overcome their obstacles. Thus, teachers should be adequately prepared to deal with 
students' failure and the sense of inadequacy felt when teachers fail to influence students' learning. Similarly, Ashton and Webb (1986) proposed that different situations may change a teacher's efficacy beliefs. For instance, a teacher's sense of personal teaching ability can be changed if a teacher is able to teach a difficult concept to a child previously believed to be incapable of learning and this also changes the teacher's sense of teaching efficacy and the belief that the students are incapable of learning.

Additionally, Raudenbush, Rowan, and Cheong (1992) found that teachers who worked in collaborative environments or perceived some form of control over their working conditions have high self efficacy. Also, the high school teachers sampled differed in their levels of efficacy based on the classes taught, with teachers in honors classes having higher efficacy than vocational teachers and general track teachers, which was highly dependent on student engagement. A plausible explanation for this difference could be the level of cooperation from students and their willingness to learn which might be highly exhibited in honors classrooms. Hence, this result further supports the notion that teacher efficacy is tied to student achievement. A teacher's belief in helping a student achieve academic success is expectedly higher in honors classes than in classes where students have low ability.

\section{Factors that affect Teachers' Efficacy}

People increase their self efficacy when their experiences disconfirm beliefs about what they fear, and they gain new skills to manage threatening activities (Bandura, 1986). Dembo and Gibson (1985) proposed that in order to increase teachers' efficacy, teachers should be provided with proper feedback about their performance, and programs should be developed to help beginning teachers' transition from student teaching to full time 
teachers. Furthermore, preservice teachers should be provided with a variety of experiences in different contexts, and also preservice teachers should be equipped with strategies to deal with student failures and to recognize their sense of inefficacy.

Woolfolk, Rosoff, and Hoy (1990) studied inservice teachers' self efficacy and their beliefs about managing students, and discovered that teachers with high efficacy had a greater tendency to surrender control and made the effort to work with students to solve classroom management problems. Similarly, Lee, Dedrick, and Smith (1991) found that teachers' major source of efficacy was intrinsically motivated. Teachers' sense of control in their classrooms and the ability of their students were more highly related to teachers' efficacy than extrinsic factors such as salaries. The results from these studies suggest that teachers' school environments are linked to their efficacy beliefs. Hence, fostering cooperative environments in the schools, and providing teachers with autonomy in classroom practices are both linked to teachers' efficacy.

A study of the efficacy beliefs of novice and experienced teachers by TschannenMoran and Woolfolk-Hoy (2007) found that novice teachers had lower self efficacy than did experienced teachers. Additionally, experienced teachers had higher self efficacy beliefs in classroom management and instructional strategies than in student engagement. These results suggest that teachers experiences working with students, achieving success in managing the classroom, and improving instruction increased teachers' efficacy. Furthermore, Tschannen-Moran and Woolfolk-Hoy observed that novice teachers who had fewer mastery experiences depended on other sources such as vicarious experiences, verbal persuasion, and emotional arousal to evaluate their self efficacy beliefs. 
Swackhamer, Koellner, Basile, and Kimbrough (2009) set out to examine whether increasing inservice teachers' knowledge of a content area would increase their self efficacy. Results of the study indicated that the teachers who took four or more courses had increased efficacy in teaching outcome than those teachers who had taken one to three courses. Overall, the teachers in the sample had high personal teaching efficacy, and increased content knowledge only increased beliefs in their ability to reach all students in the classroom. Hence, increasing content knowledge can enhance teachers' beliefs in their teaching outcomes.

Similarly, Tschannen-Moran and McMaster (2009) investigated whether four professional development formats could significantly increase inservice teachers' self efficacy. The formats examined were information; information and modeling; information, modeling, and practice; and information, model, practice, and coaching. The first three formats were shown to increase efficacy; however, the fourth format which included coaching was demonstrated to have the most effect on teachers' efficacy. Hence, mastery experiences with teachers using the strategy in their own classroom with the help of a coach significantly increased teachers' self efficacy. The study showed that gaining knowledge or even practicing the new strategy does not have a significant effect on teachers' efficacy as much as having someone coach them while implementing the strategy to ensure success is attained.

The effect of length of student teaching on preservice teachers' efficacy was explored by Chambers and Hardy (2005). The researchers examined whether engaging in one semester or two semesters of student teaching would affect preservice teachers' efficacy and found no significant difference between two groups. Chambers and Hardy 
concluded that length of student teaching does not influence self efficacy. However, these results require further exploration, and comparison with other factors would produce a more adequate conclusion.

Similarly, Gurvitch and Metzler (2008) investigated whether a laboratory or field based practicum experience would have significant effects on preservice teachers' efficacy beliefs. Those participants in the laboratory based experience showed high efficacy especially after their student teaching semester, where they demonstrated competency in a real teaching setting. In the same way, the field based students efficacy increased as their experiences in the field increased. The study showed that as long as preservice teachers experience authentic field experiences that strengthen their beliefs in their abilities in the classroom, self efficacy beliefs would increase.

McDonnough and Matkins (2010) also studied the role of field experiences and supervisors in increasing preservice teachers' self efficacy. Participants had overall high efficacy in teaching science; however, the preservice teachers engaged in practicum experience concurrently with the methods class showed significant increase in their selfefficacy. This difference in efficacy beliefs suggests that learning new material and getting to practice the strategies taught with the assistance of a supervisor greatly enhances preservice teachers' self efficacy particularly in science teaching.

\section{Efficacy in Specific Teaching Contexts}

Teaching efficacy plays a significant role in teachers' ability to teach in certain context areas. An area of concern for example is in the teaching of science. It is believed that teachers with high self efficacy would put in more effort to utilize various strategies and teaching methods to make science meaningful to students (Carleton, Fitch, \& 
Krockover, 2008; Carrier, 2009). Cannon and Scharmann's (1996) study of elementary preservice teachers identified the benefits of working in collaborative groups. Collaborative field experiences were shown to have a positive impact on teachers' efficacy. Carrier (2009) also identified the benefits of a collaborative field experience. Elementary teachers were enrolled in a summer science program, where they first observed the camp counselors engaged in activities and then the teachers were allowed to teach the students in collaboration with other teachers. The study showed that teachers' confidence in teaching science increased as a result of the field experience. This increase in confidence was attributed to the positive feedback the teachers' received from the students.

Similarly, Duran, Ballone-Duran, Haney, and Beltyukova (2009) studied inservice teachers who reported strong beliefs in their ability to teach science but were concerned about the limited resources available to them. The study aimed to examine any changes in teachers' beliefs after being enrolled in a professional development program. The study showed that teachers' efficacy was enhanced by the positive experiences from the professional development program. Conversely, Plourde (2002) found that preservice teachers' beliefs in outcome expectancy after student teaching decreased because of their experience. The students experienced lack of resources, time, support, and classroom management difficulties. These experiences however did not affect teachers' belief in their abilities. Thus, field experience is presumed to serve as a reality check and provide teachers with information about what to expect in the classroom.

Moreover, the nature of the teachers' field experience, either positive or negative, serves as a factor in enhancing teachers' efficacy. Carleton et al. (2008) enrolled teachers in a summer program to examine any significant impact of a professional development 
program on teachers' self efficacy. The participants showed a significant increase in their positive attitude about teaching science after completing the program. The teachers' attitudes were especially positive after an extensive summer session, but declined after the teachers went into the classroom and experienced barriers, such as lack of resources, in implementing the strategies learned during the program.

Cone (2008) explored the possible impact of a community based program on improving science teachers' efficacy. Preservice teachers were given a lecture and exposed to demonstrations of the lesson. After this training, the participants were allowed to teach the students directly in collaboration with other participants. The results of the study showed a gain in preservice teachers' confidence after the program. The receipt of immediate feedback from the students and instructors, and the collaborative group work among participants were considered important factors in increasing the teachers' confidence.

Bleicher (2007) recommended that novice teachers should be provided with extensive guidance in order to improve their confidence in teaching science. Preservice teachers' efficacy was examined before and after participation in a science teaching methods course. Teachers' self efficacy improved after the course, and teachers reported greater confidence about teaching science after exposure to the modeling strategies where they were provided with feedback and allowed to engage in hand on experiences.

Hence, the results of these studies imply that a collaborative structure during inservice would benefit teachers by improving their efficacy in their ability to teach science. This approach can also be utilized with teachers who are faced with the responsibility of working with students with disabilities. The positive influence of field 
experiences and exposure to alternative strategies can also be incorporated in teacher training programs to enhance preservice teachers' efficacy for working with students with EBD.

\section{The Influence of Collective Efficacy on Self Efficacy}

Collective efficacy influences what people choose to do as a group, how much effort they put into achieving a common goal and the staying power when the group efforts fail to achieve the goal. The strength of groups and organizations depends on the individual members' sense of collective efficacy that they can improve their lives and solve their problems through a combined effort (Bandura, 1986). Within the school environment, collective efficacy affects the school's overall performance. A principal's strength is dependent on the ability to get the staff working as a group and to believe in their ability to surpass obstacles towards academic achievement of students (Bandura, 1997).

Zaccaro, Blair, Peterson, and Zazanis (1995) described collective efficacy as a belief in combined competence shared among the individuals of the group when organizing their resources in a concerted effort to meet the demands of their current situation. Thus, an individual's actions are completely dependent on the actions of others when trying to accomplish a collective outcome. Furthermore, the sense of collective efficacy is obtained based on the individual's prior experience of success within the group and the influences operating within the group. Hence, if the individual experiences success within the group based on a collective effort from the group, this increases individual efficacy (Zaccaro et al., 1995). 
Researchers have sought to examine and confirm whether collective efficacy has a significant impact on individual self efficacy. Woolfolk and Hoy (1990) recognized that beginning teachers are concerned about how they as teachers are controlled by the organization in which they work. Those beginning teachers who expect to be good teachers anticipate being loyal members of the school organization. Hence, a sense of collective efficacy is important in helping beginning teachers in their early career development. Studies examining the link between collective efficacy and teachers' self efficacy have found that teacher efficacy was higher in the schools with higher collective efficacy. In schools where there is a collective effort for success, teachers will have stronger beliefs in their abilities (Goddard \& Goddard, 2001; Kurz \& Knight, 2003).

Skaalvik and Skaalvik (2007) recognized that stressors affecting teachers include working with students with behavioral problems, conflicts with colleagues, reorganizing their teaching strategies as to conform to working in teams, and school reform. Teacher self efficacy was seen as a mediator between collective efficacy and teacher burnout. Additionally, a strong negative correlation was found between self efficacy and teacher burnout. These results indicate that some of the major stressors of teachers come from the school environment and the relationship among colleagues. Thus, it is important for teachers to have a high sense of personal efficacy and collective efficacy as this is essential in reducing the chances of teacher burnout.

Additionally, Goddard and Goddard (2001) explored whether mastery experiences influenced teachers' perception of collective efficacy, and whether collective efficacy affected student achievement. This was a longitudinal study which examined students' score on a state administered exam. The study showed collective efficacy was significantly related to differences in student achievement across the various schools, and 
past school performance was related to teachers' perception of collective efficacy. Schools in which teachers had a higher sense of collective efficacy produced higher student achievements. Also, the study showed that mastery experiences are strongly related to collective efficacy. Hence, the more success teachers achieved with their students the higher their belief in the concerted effort found in the schools, and the belief that all teachers are working to meet a common goal.

Similarly, Klassen (2010) in a study of teachers' stress levels and the mediating effects of collective efficacy found that teachers' belief in the collective efficacy to control student misbehavior significantly reduced job stress related to students' behavior. This suggests that efforts to formulate a school wide plan to control students' behavior and easing the individual burden on the teacher to manage students' behavior will significantly reduce teachers' stress and enhance job satisfaction.

\section{Efficacy and Burnout}

Persons with high efficacy are more likely to persist in their efforts until they succeed and will thus suffer less from burnout (Bandura, 1982). Moreover, persons with high efficacy will try to establish some form of control over their environments whereas those with low efficacy believe their efforts would be futile and may give up completely (Bandura, 1997). Similarly, Bandura (1982) suggested that persons with high selfefficacy will increase their efforts in order to succeed or may try to change the environment. When persons with high efficacy are placed in environments that are unresponsive to their efforts it leads to resentment, protest, and a collective effort to effect change. These persons will eventually leave the environment and seek more favorable environments if they perceive change as impossible to achieve. 
Subsequently, teachers with low self efficacy, especially younger teachers, are more likely to experience burnout, since self efficacy serves as a buffer for stressors from the job and decreases burnout (Schwarzer \& Hallum, 2008). Burnout is described as a delayed reaction to the emotional and interpersonal stressors encountered on the job. Burnout is characterized by exhaustion, detachment from the job, feelings of pessimism and ineffectiveness, and lack of accomplishment. Persons who are burned out feel incompetent and are thus less productive on the job (Maslach, Schaufeli, \& Leiter, 2001). Accordingly, Taylor and Tashakkori (1995) found that job satisfaction increased when teachers dealt with academically capable students who were well behaved and further when the teachers perceived their work environment to be free of constraints such as arduous routines. Also, job satisfaction was dependent on a satisfactory school climate such as lack of barriers to teaching, and being given the opportunity to partake in the decision making process. Moreover, Coladarci (1992) found greater commitment among teachers in schools with fewer students per teacher, and also in schools where the principal was regarded positively. Schools where the principal maintained a good relationship with the students and staff, and included teachers in decision making were seen to have more dedicated teachers.

Chester and Beaudin (1996) in their comparison study of newly hired teachers observed that perceived collaboration among teachers increased teachers' self efficacy. Also, teacher efficacy was enhanced by the availability of opportunities for collaboration, attention from supervisors, and the availability of resources for instruction. Similarly, Taitt (2008) recognized that teacher resilience is dependent on certain factors within the teacher and within the context of the school environment. These factors include rebounding after a difficult experience, learning from experiences, setting future goals, 
self care, embracing opportunities for personal growth offered within the school, utilizing problem solving strategies, and maintaining a sense of optimism. Additionally, BrayClarke and Bates (2003) noticed that schools that required teachers to develop their own individualized professional development plans, where the teachers received effective feedback and the teachers shared responsibility for school goals and student achievement were better able to enhance teachers' efficacy.

Subsequently, Hong (2010) studied teachers at various levels of their teaching careers to determine any differences in their identities as teachers and their sense of commitment, value and efficacy. The sample included preservice teachers before and after student teaching, beginning teachers with five years or less experience, and beginning teachers who had left the profession. The results showed that the teachers differed significantly with the preservice teachers who had not experienced student teaching showing the highest belief that they would experience less burnout. The teachers who had left the profession had low commitment, weaker efficacy, more burnout, and negative perception of power relations within schools. The results of the study imply that the more experience a teacher has in schools the greater the chances of burnout. Also, low efficacy beliefs were linked to difficulties in managing the classroom, which increased stress and burnout.

In a similar study, Klassen and Chiu (2010) explored the effect of years of teaching experience on teachers' self efficacy and the possible stressors affecting teachers. The participants' years of experience ranged from beginning teachers to over 10 years experience and the teachers came from various school types. Teachers' efficacy for classroom management increased with years of experience, peaking at 23 years of service and declining afterwards. Teachers in elementary schools had higher classroom 
management efficacy than teachers in secondary schools. Efficacy in instructional strategies and student engagement also increased with years of experience. The results of the study confirmed that years of experience and job related stress had a significant relationship with teachers' self efficacy and are linked to job satisfaction. Teachers with high overall stress reported lower job satisfaction, and those with high levels of efficacy for classroom management and instructional strategies reported higher job satisfaction. The results also indicated that teacher efficacy increases with years of teaching but declines by late career and this decline may be attributed to teacher burnout.

\section{Self Efficacy and the Teacher- Student Relationship}

Yoon (2002) found that teachers' stress was correlated with negative affect, self efficacy, and negative relationships with students. Also, teachers' stress levels were predictive of the number of students with whom they had negative interactions. The amount of stress a teacher experiences increases the likelihood of the teacher displaying negative affect which is interpreted as adversarial to students and leads to negative reactions from the students. Moreover, Pianta (1995) recognized that students who are most likely to be referred for special education are those students who are in conflict with their teachers. However, those who are in need of referral but are not referred have notable closer relationships with their teachers. This difference in the probability of referral indicate the significant role that student- teacher relationships plays in a teacher's likelihood to refer a child for special education services.

Soodak and Podell (1994) found that teachers frequently look to outside sources such as counselors for assistance in meeting the needs of difficult to teach students. Teachers who had higher efficacy were more prone to utilizing strategies within the 
classroom and were less often to seek external sources of help. However, those teachers who were willing to engage students in their classrooms believed their instructional strategies were ineffective and believed addressing the students emotional needs would be more beneficial. Likewise, Hughes, Barker, Kemenoff, and Hart (1993) found that teachers with higher efficacy reported seeking to solve problems with difficult students on their own without referrals or consultation with other service providers. Hence, a teacher's sense of efficacy continues to be a significant factor in a teacher's willingness to work with students with disabilities in their classrooms.

Subsequently, Buell, Hallam, Gamel-Mccormick, and Scheer (1999) surveyed both general and special education teachers and found that in both teacher groups an understanding of inclusive education impacted their beliefs in their ability to help students succeed. However, general education teachers expressed not having the necessary support and resources to successfully integrate special needs students in their classrooms. On the other hand, the special education teachers reported more confidence and preparation for including students with disabilities in general classroom settings.

Shippen et al. (2005) found that general education teachers had higher anxiety levels than special or dual education teachers; however, this anxiety decreased with additional knowledge. This suggests that further training and field experiences interacting with students with disabilities would greatly enhance general education teachers' efficacy for working with students with disabilities in their classrooms. Also, enhancing teachers' efficacy would lead to greater job satisfaction and better teacherstudent relationships (Viel-Rumal, Houchins, Jolivette, \& Benson, 2010). 
Woolfson and Brady (2009) suggested that teachers bring their own beliefs and expectations about teaching students with disabilities to the classroom. Their examination of teachers' beliefs showed that teachers with high efficacy saw students' difficulties as changeable and believed students had a greater degree of control over their difficulties. Interestingly, the study showed that increasing teachers training or knowledge did not impact teachers' efficacy or their beliefs in coping with students with learning disabilities in their classrooms. Hence, based on these findings it can be concluded that professional development is not a sole contributor in changing teachers' beliefs; positive experiences with these students may also play a significant role in altering teachers' beliefs and expectations.

In order to explore teachers' efficacy beliefs and expectations and how they relate to their students, Whitley (2010) studied teachers from various grades, with a wide range of teaching experiences, and differing levels of special education training. The study showed that student achievement was directly affected by teachers' expectations. Students with learning disabilities had lower achievement, and their teachers had lower expectations and self efficacy. Teachers' training in special education had a small positive impact on teachers' self efficacy. These differences in teachers' efficacy and students' achievement demonstrate that teachers may have preconceived notions about students with disabilities and that additional knowledge or experience may not necessarily alter their beliefs. However, this view is not supported by Main and Hammond (2008) who found that preservice teachers have generally a high sense of efficacy and this efficacy increased after practicum. It was recognized that classroom 
exposure enhanced preservice teachers' self efficacy although previous behavioral management skills were not utilized for more challenging or persistent behavioral problems.

\section{Summary}

Teachers' self efficacy is the belief that the teacher has the abilities and skills to influence student learning (Dembo \& Gibson, 1985). Teachers with high self efficacy will persevere despite the obstacles or aversive situations, whereas those with low efficacy will put forth a relaxed effort or give up entirely when faced with challenges (Bandura, 1982). Thus, it is important for teachers to be given opportunities to enhance their self efficacy such as by providing preservice teachers with a variety of experiences in different contexts, giving teachers proper feedback about their performance, and developing programs in schools to help the transition from student teaching to full time teaching (Dembo \& Gibson, 1985). Additionally, a sense of collective efficacy in schools boosts individual teachers' self efficacy by enhancing teachers' beliefs in their abilities to help students succeed (Kurz \& Knight, 2003). A positive school environment where teachers are given opportunities to set their own goals, to learn from their experiences, and to experience personal growth will help decrease the stressors of the job and enhance teachers' self efficacy, thereby, decreasing the possibility of burnout and decreasing teacher attrition rates (Taitt, 2008). Furthermore, teachers' self efficacy is important for enhancing teacher- student relationships and the teacher's willingness to work with a student with emotional and behavioral disorders. Since, the students most referred for special education are those students who are in conflict with their teachers (Pianta, 1995). 


\section{CHAPTER III}

\section{METHODOLOGY}

This chapter examines the procedure for selecting the sample of preservice teachers, the instruments utilized, and instrument development. The chapter also outlines the different methods used for data collection, and the data analysis employed to answer the following research questions:

Q1 To what extent does personal experience, field experience, coursework, and knowledge of EBD predict preservice teachers' self efficacy?

Q2 Are there any differences among special education and general education teacher programs with regards to knowledge of emotional and behavioral disorders?

Q3 Are there any differences in preservice teachers' knowledge of EBD and self efficacy across the different teacher education programs?

Q4 Does practicum experience and exposure to a student diagnosed with EBD during the practicum experience influence preservice teachers' efficacy in student engagement?

\section{Sample Selection}

Participants in this study included a convenience sample of preservice general and special education teachers, both male and female, enrolled in undergraduate fall classes in a mid-sized Midwestern university, located in a mid-sized city. The sample included preservice teachers in the Elementary (K-Grade 6), Secondary (Grades 7-12), PostBaccalaureate Licensure in Elementary Education, and Special Education Generalist (KGrade 12) programs. 
Meetings were held with the Associate Dean of Teacher Education and the different program coordinators to help identify the best sample for use in achieving the aim of this research. The preservice teachers are all required to complete four courses which address emotional and behavioral disorders in students. These courses are Educational Psychology, Educational Technology, Foundations of Education, and one or more Special Education courses. These courses do not discuss EBD in depth, but provide an overview of the different disorders affecting students in the classroom.

The students in the post-baccalaureate program are graduate level preservice teachers. These students already possess degrees in other fields and have decided to pursue careers as teachers. The sample from the post-baccalaureate program was enrolled in either the Educational Psychology or Foundations of Education courses. It was important to include these students as they constitute a significant number of teacher candidates. Consequently, to adequately compare across programs, students classified as juniors and seniors or those preparing for student teaching were recruited to partake in this research.

The students in the elementary program were enrolled in Literacy Practicum. This practicum includes field placement, where the students observe teachers in the classroom. The field experiences also require the preservice teachers to teach three lessons and to actively participate in the classroom, but the main focus is on observing instruction at different grade levels. The nature of the field experience is dependent on the classroom teacher; thus, some teacher candidates may be given the opportunity to interact with the students while others may spend more of their time doing administrative duties. Additionally, the field experiences focus on exposing preservice teachers to different strategies for providing necessary accommodations to students with disabilities. 
Upon successful completion of the practicum, the teacher candidates enroll in student teaching. These students in the Literacy Practicum vary in whether they have completed their necessary coursework or field experiences and were identified by the program coordinator as the best sample for this research.

The students in the secondary program were all enrolled in the Professional Teaching Education Program (PTEP) seminars. These students are preparing for student teaching assignments and vary in their experiences. The practicum experience includes observing classrooms, interacting with students, or teaching a lesson. The nature of the students' field experiences is dependent on the classroom teachers. The aim of the field experience is to provide preservice teachers with classroom experiences focused on special education, multicultural education, and classroom instruction and management. The teacher candidates observe teacher-student interactions and are exposed to strategies for addressing diversity in the classroom. The PTEP seminars were identified by the Associate Dean of Teacher Education as the best option for having direct contact with the teacher candidates before they enroll in student teaching.

The special education teacher candidates were enrolled in the Behavioral Dimensions of Students with Exceptionalities courses. These are two special education courses which focus on the assessment of students' behavioral difficulties. The program coordinators suggested that the students enrolled in these courses vary in whether they had previous field experiences or coursework and would serve as the best sample for use in this research.

\section{Instruments}

Teacher Self Efficacy Scale. The Teacher Self Efficacy Scale (TSES) long form was administered to the participants. The TSES was developed by Tschannen-Moran and 
Woolfolk- Hoy (2001) based on Bandura's definition of self efficacy. Both the teacher's analysis of the teaching task and the teacher's assessment of personal teaching competence are incorporated into the TSES. Participants are required to indicate, based on a 9-point Likert scale, their opinions of the 24 statements presented. The responses are anchored with the descriptors 1-nothing, 3-very little, 5-some influence, 7-quite a bit, and 9-a great deal. The statements presented are related to three domains- instructional strategies, classroom management, and student engagement. Each domain included eight questions such as,

- Efficacy in instructional strategies- \#11 ("To what extent can you craft good questions for your students?") and \#18 ("How much can you use a variety of assessment strategies?")

- Efficacy in student engagement- \#2 ("How much can you do to help your students critically?") and \#4 ("How much can you do to motivate students who show low interest in school work?")

- Efficacy in classroom management- \#3 ("How much can you do to control disruptive behavior in the classroom?") and \#13 ("How much can you do to get children to follow classroom rules?').

The TSES has been shown to include elements of concurrent and construct validity. The internal consistencies of all the scales were typically .80 (Heneman, Kimball, \& Milanowski, 2006; Tschannen-Moran \& Woolfolk-Hoy, 2001).

Knowledge of Emotional and Behavioral Disorders Questionnaire. The current researcher compiled a self-report questionnaire for the purpose of this study, since finding a measure to use proved difficult due to the dearth in the research on teachers' knowledge of EBD. Preservice teachers' knowledge was assessed based on how much they knew about EBD, their ability to successfully identify the symptoms of the disorder in students, and their knowledge of appropriate strategies for handling students' behavior in the classroom. 
The questions formulated for this questionnaire are based on the diagnostic criteria of emotional and behavioral disorders found in the American Psychiatric Association (APA) Diagnostic and Statistical Manual of Mental Disorder (DSM-IV-TR) (APA, 2000), information presented on the American Academy of Child Adolescent Psychiatry website (AACP, 2010), and from Pierangelo and Giuliani (2008). The original questionnaire included seven multiple choice questions based on vignettes, which required participants to use their knowledge or experience of EBD to choose the best possible explanation for the child's behavior. Also, there were 13 factual statements about emotional and behavioral disorders (e.g., Antidepressants are not administered to children as part of treatment for depression; Children with ADHD cannot sit still long enough to pay attention). Participants were required to rate these statements as either true or false.

Reliability and validity of the Knowledge of EBD questionnaire. The original questionnaire was administered to three professionals in the field of psychology, teacher education, and statistics and measurement for review of the questionnaire content. The questionnaire was also administered to six students in various fields including education, special education, educational psychology, business, and engineering to assess the appropriateness and wording of the questions, ease or difficulty of answer choices, and to provide an indication of the required time to complete the questionnaire. No changes were made to the questionnaire following these reviews. The questionnaire was then piloted to establish the reliability and validity of the scores from the measure.

In the first pilot study, 37 senior undergraduate preservice general education students were administered the EBD questionnaire, and a reliability analysis was conducted with all 20 knowledge items. The results of the reliability analysis revealed an 
overall Cronbach's $\alpha=.269$. Field (2009) recommends examining the Cronbach's Alpha if Item Deleted table for indications of the change in the overall alpha if particular items are deleted. The deletion of these items would improve reliability. The Cronbach's Alpha if Item Deleted table indicated that the reliability of the measure would improve if items 4,11 , and 18 were deleted. These items were deleted individually and the Cronbach's $\alpha$ re-examined. There were 17 items in the measure with an overall Cronbach's $\alpha=.511$. Based upon non-normal distributions, two further items 7 and 19 were deleted. Thus, the final questionnaire encompassed 15 items.

This 15 item questionnaire was further piloted with a sample of 84 preservice undergraduate general education students in various education programs, ranging in university classification from junior to senior. A reliability analysis was conducted with all 15 knowledge items and an overall Cronbach's $\alpha=.321$ was obtained. An examination of the Cronbach's Alpha if Item Deleted table revealed that if items 5, 9, and 6 were deleted the reliability of the measure would improve. Subsequently, these items were individually deleted and the Cronbach's $\alpha$ reexamined. The final measure contained 12 items with an overall Cronbach's $\alpha=.462$. The low reliability of participants' scores on the knowledge questionnaire suggest that participants found the test items relatively easy and more difficult items should be included in the questionnaire.

Hence, in order to improve the reliability of the questionnaire, three additional items were added to the measure. Based on Pierangelo and Giuliani (2008), three vignettes were formulated which described the behavior of students with EBD in the classroom. Participants were required to indicate which intervention was best for handling the students' behavior based on the preservice teachers' knowledge and experience of EBD. The questionnaire with the three additional items was administered 
to three of the teacher education professors to review the content and to evaluate whether the questionnaire measures teacher's knowledge of EBD. There were no changes made to the questionnaire after the review.

Hence, the final questionnaire for use in this current study included 15 items (7 multiple choice and 8 true /false items). Participants' responses were coded either 1 (right) or 0 (wrong) with the possibility of obtaining a total knowledge score ranging from 0-15 from the questionnaire.

A reliability analysis was conducted with all 15 knowledge items and an overall Cronbach's $\alpha=.158$ was obtained. An examination of the Cronbach's Alpha if Item Deleted table revealed that if item 10 was deleted the reliability of the measure would improve. Upon deletion, the Cronbach's $\alpha$ changed to .184. Further examination indicated that item 13 should be deleted, changing the Cronbach's $\alpha$ to .215 . Item 2 was also deleted and this changed Cronbach's $\alpha$ to .23. Further examination of the table resulted in the deletion of item 12 with Cronbach's $\alpha=.258$ and then item 1 with Cronbach's $\alpha=.278$. Additionally, items 8 and 7 were individually deleted and the Cronbach's $\alpha$ reexamined. The final measure contained 8 items with an overall Cronbach's $\alpha=.32$.

Subsequently, further analysis was conducted on the knowledge of EBD questionnaire to validate whether a total score or two subscale scores should be used in the analysis of the data. The 15 items were divided into two subscales, one subscale included the 7 multiple choice items and the other subscale comprised the 8 true and false questions, and a reliability analysis was conducted. The reliability analysis of the 7 multiple choice items revealed an overall Cronbach's $\alpha=.168$. An examination of the Cronbach's Alpha if Item Deleted table showed that item 2 should be deleted changing 
the Cronbach's $\alpha$ to .207 . Further examination indicated that item 1 should be deleted, changing the Cronbach's $\alpha$ to .238. Item 7 was also deleted and this changed Cronbach's $\alpha$ to .274 . The final multiple choice questions subset contained 4 items with an overall Cronbach's $\alpha=.274$.

The reliability analysis of the 8 true and false items showed an overall Cronbach's $\alpha=.015$. The Cronbach's Alpha if Item Deleted table showed that item 9 should be deleted changing Cronbach's $\alpha$ to .059. Item 14 was also deleted changing Cronbach's $\alpha$ to .081. Further examination of the table resulted in the deletion of item 15, which changed Cronbach's $\alpha$ to .219. Also, deleting item 8 changed Cronbach's $\alpha$ to .271 , and finally deletion of item 12 resulted in Cronbach's $\alpha=.326$. Thus, the final true and false questions subset contained 3 items with an overall Cronbach's $\alpha=.326$. Based on these reliability analyses, it was justifiable to use the two subscale scores in further analysis.

Demographic Information Form. Participants were also asked to complete the demographic information form by providing information which pertains to gender (male or female), age, race (White, Black or African American, Asian, American Indian, Hispanic, Mixed or other), program of study (Early Childhood, Elementary, Secondary, Art, Music, Physical Education, Bilingual Bicultural Education, English as Second Language, Post Baccalaureate, or other), and classification (Freshman, Sophomore, Junior, Senior, Graduate). Participants were also required to indicate whether they have had practicum or field experience, and whether any of the students in the classroom were diagnosed with EBD. Also, participants indicated whether they worked with or known a child diagnosed with EBD and whether they have taken any special education courses or 
coursework related to EBD (Educational Psychology, Educational Technology, Special Education, Foundations of Education or other). See Appendix C for a copy of the Demographic Information form.

\section{Procedures}

This research is categorized as a quantitative study utilizing survey methods. A three-section paper and pencil survey was administered to the participants who volunteered to participate in the study. This method was used to ensure that the results obtained were impersonal and objective. The results of this study were obtained by statistical analysis in order to avoid any biases (Gall, Gall \& Borg, 2007). However, this research method limited the ability to obtain data from the participants about their personal experiences, views about emotional and behavioral disorders, and their teacher preparation experiences.

Upon receiving approval from the Institutional Review Board (Appendix E), data collection proceeded via three different methods. Since the participants in the post baccalaureate program were taking their classes in off-campus centers, it was necessary to provide the professors with the survey packets and required them to seek volunteers to partake in this research. The professors of five course sections agreed to administer the survey, and each professor received a survey packet with instructions. One professor from two of the course sections later indicated that time constraints prevented the administration of the survey. In the three other sections 39 out of a possible 75 students completed the survey. The professors returned the completed surveys to the School of Teacher Education and were collected by the researcher. This method provided the most feasible solution for contacting these teacher candidates in a timely manner. 
Secondly, for both the elementary and secondary programs and one of the special education classes, the researcher was allowed to attend a class session to administer the survey. The students were given a brief summary of the study and students willing to participate completed the survey in class. This was the case for 185 participants. The remaining participants were recruited from one special education class and the professor gave students one credit point for participating. A brief summary was given and willing participants were asked to sign up for a designated time to meet with the researcher in a research room within the School of Psychological Sciences. Out of the 25 students in the class, 8 volunteered but only 6 students participated in the study.

Participants first received the consent letter (Appendix A) in which described individual rights, ensured confidentiality, and broadly outlined the activities involved in the study. After addressing any concerns or questions, the participants received the questionnaire packet. Firstly, participants were required to complete Section I, the Teacher Self Efficacy Scale, where they indicated the extent to which they agree with 24 statements related to working and managing students with EBD in their classrooms. Participants then completed Section II, the Knowledge of EBD questionnaire, by answering 15 questions based on their knowledge of students with emotional and behavioral disorders. See Appendix B for a copy of the questionnaire. Finally, the participants were required to complete Section III, by providing demographic information such as gender, age, program of study and previous experience working with children diagnosed with EBD.

Completion of the entire survey took approximately 20 minutes. Participants were asked to place finished surveys in a file box provided and this box was placed in my academic advisor's locked office. Participation in the study was voluntary and 
participants were free to withdraw at any point. All efforts were made to ensure that data collected remained confidential and since students were not required to provide their names or signatures, no indentifying markers were used during analysis and summary. Participants were provided with a Debriefing form (Appendix D), explaining the study and providing supplemental information to address any questions that may arise after partaking in the study.

\section{Data Analysis}

Participants' responses on the demographic questionnaire were coded based on the different sections. Categorical variables such as race and program of study were numbered 1-12 based on the number of items in each section. Participants' responses on practicum experience, familiarity with a child diagnosed with EBD, and relevant coursework items were coded as $0(Y e s)$ or $1(\mathrm{No})$. Practicum experience, familiarity, and relevant coursework served as three of the independent variables used in the analysis. Participants' responses on whether or not students in the practicum classroom were diagnosed with EBD were also coded as $0($ Yes) or $1(\mathrm{No})$. Missing data were coded as 99 and 66 for non applicable data in the Microsoft Excel file. This Excel file was imported into the SPSS.19.0 program for analysis.

Participants' responses on the TSES were entered into the Excel data file based on their responses on the Likert scale. Participants received a composite score for their efficacy in each subscale. On the Knowledge of EBD questionnaire, participants' answers on the multiple choice questions were entered as 1-4 representing the choices $a$ d. On the true and false sections, responses will be coded as 1 (True) and 2 (False). These responses were later recoded as 1 (correct) and 0 (incorrect). Participants received a total knowledge score based on their number of correct responses. As part of the 
preliminary analysis, the data obtained were scrutinized to detect any errors in data entry. Frequencies were computed on the data to obtain the general distribution of responses and to observe for any abnormal patterns.

\section{Factor Analysis and Reliability Analysis of TSES}

A principal component analysis (PCA) was conducted on the 24 items of the TSES. A PCA helps to establish the linear components existing in the data and the variables associated with each component (Field, 2009). The Kaiser-Meyer-Olkin measure verified the sampling adequacy for the analysis, $\mathrm{KMO}=.926$. Bartlett's test of sphericity $\chi^{2}(276)=2602.548, p<.001$, indicated that correlations between items on the test were large for PCA.

The Kaiser rule of retaining factors with eigenvalues greater than 1 was used for factor extraction. This rule is based on the idea that an eigenvalue of 1 represents a significant amount of variation explained by a factor (Field, 2009). The scree plot was also used to verify the number of factors retained. The orthogonal rotation (varimax) was utilized to maximize clustering of the items. Four components had eigenvalues greater than 1 and combined to explain $57.2 \%$ of the variance. The scree plot indicated that either three or four factors should be retained. The factor loading tables showed that the items clustered onto four factors and further justified the use of four factors. This is contradictory to the three subscales designated by Tschannen-Moran and Woolfolk-Hoy (2001); however, the items that cluster under the same components indicate that component 1 represents the efficacy in instructional strategies subscale, component 2 represents efficacy in classroom management subscale, component 3 represents efficacy 
in student engagement, and component 4 represents items linked to efficacy in instructional ability. Table 1 shows the factor loadings after rotation with all values less than .40 suppressed.

Table 1

Factor Loadings for Exploratory Factor Analysis for TSES

\begin{tabular}{|c|c|c|c|c|}
\hline & \multicolumn{4}{|c|}{ Component } \\
\hline & 1 & 2 & 3 & 4 \\
\hline SE18 & .800 & & & \\
\hline SE17 & .690 & & & \\
\hline SE23 & .659 & & & \\
\hline SE24 & .544 & & & \\
\hline SE22 & .501 & & .428 & \\
\hline SE20 & .482 & & & .449 \\
\hline SE12 & .453 & & & \\
\hline SE13 & & .796 & & \\
\hline SE15 & & .692 & & \\
\hline SE16 & & .660 & & \\
\hline SE19 & .442 & .646 & & \\
\hline SE21 & & .596 & & \\
\hline SE3 & & .527 & .431 & \\
\hline SE14 & & .473 & .414 & \\
\hline SE4 & & & .732 & \\
\hline SE1 & & & .715 & \\
\hline SE6 & & & .640 & \\
\hline SE2 & & & .583 & \\
\hline SE9 & & & .545 & \\
\hline SE5 & & & & .700 \\
\hline SE7 & & & & .616 \\
\hline SE11 & .461 & & & .589 \\
\hline SE8 & & .477 & & .541 \\
\hline SE10 & & & & .524 \\
\hline
\end{tabular}


An analysis was conducted with the 24 teacher self efficacy items and again with the subscales to establish the reliability of the TSES for use with this sample. The results of the reliability analysis revealed an overall Cronbach's $\alpha=.935$. The reliability analyses for the 4 subscales are displayed in Table 2.

Table 2

TSES subscale distribution and reliability

\begin{tabular}{lll}
\hline Subscale & Test Items & Cronbach's Alpha \\
\hline Instructional Strategies & $12,17,18,20,22,23,24$ & .828 \\
Classroom Management & $3,13,14,15,16,19,21$ & .884 \\
Student Engagement & $1,2,4,6,9$ & .812 \\
Instructional Ability & $5,7,8,10,11$ & .761 \\
\hline
\end{tabular}

\section{Factor Analysis of the Knowledge of EBD Questionnaire}

A factor analysis was conducted on the Knowledge of EBD questionnaire to explore the linear components existing in the data. A principal component analysis (PCA) was conducted on the 15 items on the questionnaire. The Kaiser-Meyer-Olkin (KMO) measure was used to verify the adequacy of the sample for the analysis, KMO = .504. The value of KMO indicated that correlations between items on the test were not large enough for PCA. Field (2009) suggest that in order for the sample to be adequate for factor analysis, the KMO values should be at least .7. However, Bartlett's test of sphericity $\chi^{2}(105)=164.016, p<.001$ is significant and suggests that there is some correlation between the variables. Also, examination of the correlation matrix revealed no correlation greater than .3 which further indicates that a factor analysis is not appropriate for this data. However, since there were no correlations greater than .9 , there 
is no issue of multicollinearity in the data (Field, 2009). Additionally, the scree plot was difficult to interpret as no stable plateau is exhibited. See Figure 1 for the scree plot of the items on the knowledge of EBD questionnaire.

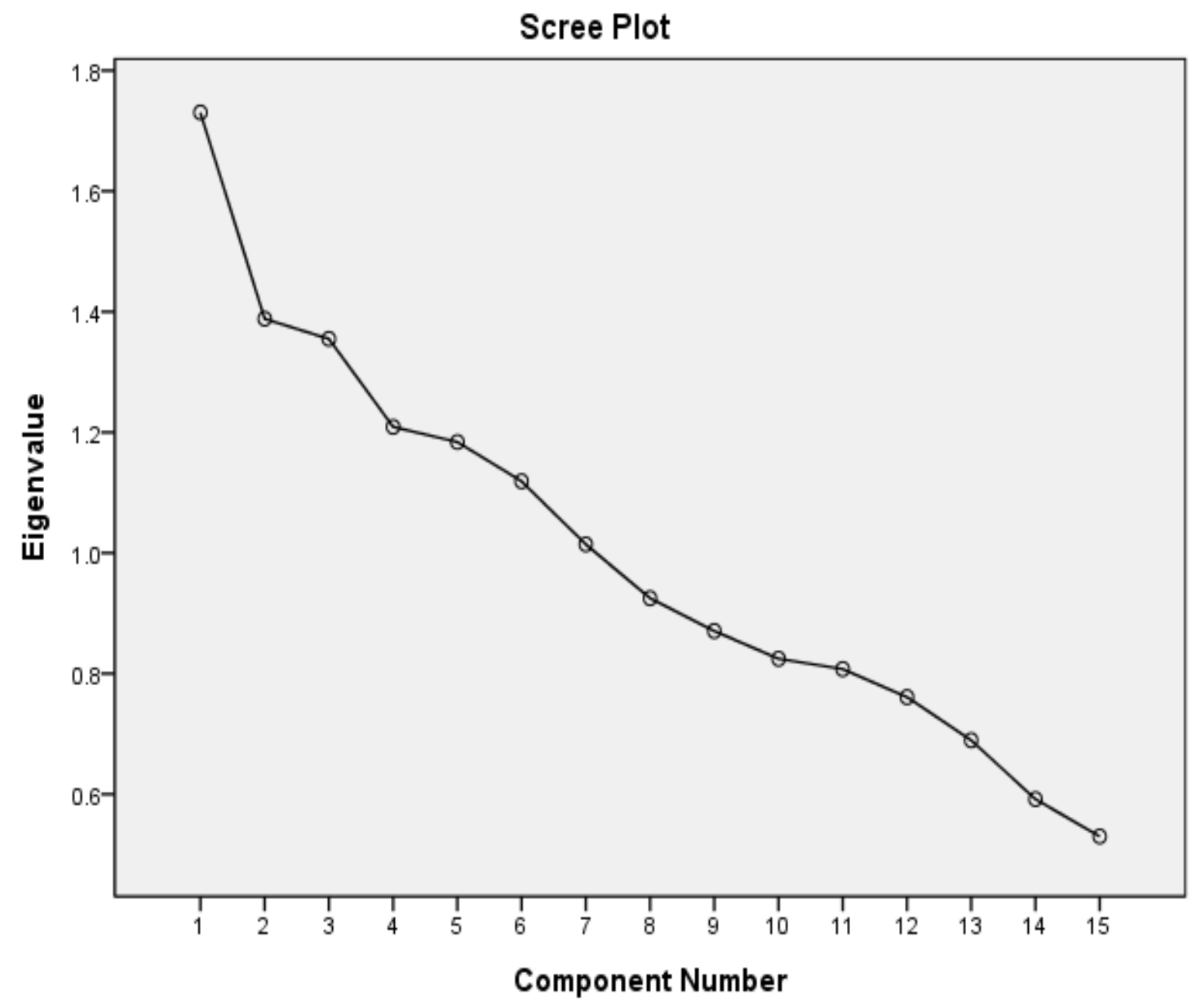

Figure 1. Scree plot for Knowledge of EBD items

\section{Inferential Statistical Procedures}

As part of the exploratory analysis, three separate $t$-tests were conducted to explore for any differences between participants' responses on the variables practicum experience, familiarity with a child diagnosed with EBD, and relevant coursework when 
compared against their total scores on the knowledge of EBD questionnaire. The $t$-test is a good measure for determining whether two group means are different (Field, 2009). Prior to interpreting the results of the $t$-tests, a test of the assumption of homogeneity of variance was conducted using Levene's test. For these data, Levene's test was nonsignificant with all $p$ values greater than .05 . This indicated that the variances are equal and as such, the assumption of variance was met (Field, 2009).

Additionally, to explore whether participants scores on the TSES and the Knowledge of EBD questionnaire differed based on their university classification, a Multivariate Analysis of Variance (MANOVA) was conducted. Field (2009) recommend the use of MANOVA for investigating the interactions of several independent and dependent variables simultaneously. Prior to interpreting the results of the MANOVA, the test of the homogeneity of variance was tested using Box's test. The results indicated that the assumption of homogeneity of covariance was met, since Box's test was nonsignificant with $p$ value greater than .05 (Field, 2009).

To answer the research questions, a MANOVA was conducted to determine to what extent practicum experience, familiarity, relevant coursework and knowledge of EBD influenced the participants' scores on the self efficacy measure. Additionally, to compare any group differences among the different general education programs on their knowledge of EBD and TSES score, another MANOVA was conducted. To verify whether it was appropriate to conduct a MANOVA, the test of assumption of homogeneity of covariance was performed using Box's test. The results indicated that the assumption of homogeneity of covariance was met, with Box's test non-significant with all $p$ values greater than .05 . 
To compare any differences between special education and general education teachers on their total knowledge of EBD score, a one way analysis of variance (ANOVA) was conducted to compare the means of the groups. The ANOVA is best used for exploring the differences among three or more means (Field, 2009).

A test of the assumption of the homogeneity of variance was conducted using Levene's test. The assumption of equal variance was met with Levene's test non significant with $p>.05$. Additionally, a MANOVA was conducted to evaluate whether there were any differences among the participants' in their knowledge of EBD across the different teacher education programs.

Also, to determine whether practicum experience and having a student diagnosed with EBD in the classroom influences participants efficacy in student engagement, two separate $t$-tests were conducted. Levene's test was non-significant with all $p$ values greater than .05 , which indicated that the assumption of variance was met. Further, a discriminant analysis was conducted using the variable field experience and either the multiple choice or true and false questions, to determine which question type best discriminated between those participants who had previous field experience and those who had no previous field experience.

\section{Summary}

This research was quantitative in nature. The participants included a convenience sample of teacher candidates in the elementary, secondary, special education, and post baccalaureate programs enrolled in fall classes in a mid size university in a Rocky Mountain state. Participation in this study was voluntary and all efforts were made to ensure the confidentiality of the data collected. 
The Teachers' Sense of Self Efficacy Scales (TSES) long form developed by Tschannen-Moran and Woolfolk-Hoy (2001) based on Bandura's definition of self efficacy was used in this study. The other instrument used in this study was a questionnaire developed for the purpose of this study based on the diagnostic criteria of emotional and behavioral disorders found in the American Psychiatric Association (APA) Diagnostic and Statistical Manual of Mental Disorder (DSM-IV-TR) (APA, 2000), information presented on the American Academy of Child Adolescent Psychiatry website (AACP, 2010), and from Pierangelo and Giuliani (2008). This questionnaire was piloted in two other studies before use in this current study. The data collected were analyzed and presented using descriptive and inferential statistics. The results provide information about the participants' experiences in the teacher education program, their knowledge of EBD, and their self efficacy. 


\section{CHAPTER IV}

\section{RESULTS}

This chapter presents the findings of the study. Firstly, a description of the sample used in this study and the information presented in the demographic data form are provided. Also, the participants' responses on the survey instruments are outlined. The answers to the following questions are also presented:

Q1 To what extent does personal experience, field experience, coursework, and knowledge of EBD predict preservice teachers' self efficacy?

Q2 Are there any differences among special education and general education teacher programs with regards to knowledge of emotional and behavioral disorders?

Q3 Are there any differences in preservice teachers' knowledge of EBD and self efficacy across the different teacher education programs?

Q4 Does practicum experience and exposure to a student diagnosed with EBD during the practicum experience influence preservice teachers' efficacy in student engagement?

\section{Participants}

The participants in this study included a convenience sample of 230 participants. The majority of participants were females (184), representing $80 \%$ of the sample. The age of the participants ranged from 19 to 51 with a mean age of 23.37 years $(S D=6.8$ years). The majority of participants were White, representing $85.7 \%$ of the sample. See Table 3 for the demographic distribution of the sample. 
Table 3

Demographic Table

\begin{tabular}{lll}
\hline Characteristic & Frequency & Percentage \\
\hline Gender & & \\
Male & 46 & 20.0 \\
Female & 184 & 80.0 \\
Total & 230 & 100.0 \\
Age & & \\
19 & 3 & 5.7 \\
20 & 42 & 18.3 \\
21 & 70 & 30.4 \\
22 & 35 & 15.2 \\
23 & 16 & 7.0 \\
$24-29$ & 22 & 10.4 \\
$30-40$ & 15 & 7.3 \\
$41-51$ & 10 & 4.2 \\
Missing & 3 & 1.3 \\
Total & 230 & 100.0 \\
Race & & \\
White & 197 & 85.7 \\
Black & 1 & .4 \\
Asian & 1 & .4 \\
Hispanic & 21 & 9.1 \\
American Indian & 3 & 1.3 \\
Mixed Race & 3 & 1.3 \\
Other & 2 & .9 \\
Missing & 1 & .4 \\
Total & 230 & 100.0 \\
& & \\
\hline
\end{tabular}

Of the total of 300 students asked to participate in the study, 230 completed the survey, giving a response rate of $76.7 \%$. The majority of the participants were classified as seniors (54.8\%), and participants were primarily enrolled in the Secondary Education program (53.9\%). Participants also reported having an emphasis in Music, English as a Second Language and Bilingual Bicultural Education. See Table 4 for the educational statistics of the sample. 
Table 4

\section{Educational Statistics}

\begin{tabular}{lll}
\hline Characteristic & Frequency & Percentage \\
\hline Classification & & \\
$\quad$ Sophomore & 8 & 3.5 \\
Junior & 57 & 24.8 \\
$\quad$ Senior & 126 & 54.8 \\
$\quad$ Graduate & 39 & 17.0 \\
Total & 230 & 100.0 \\
Program of Study & & \\
Elementary & 44 & 19.1 \\
Secondary & 124 & 53.9 \\
Post Baccalaureate & 38 & 16.5 \\
Special Education & 21 & 9.1 \\
Other & 3 & 1.3 \\
Music & 1 & .4 \\
English as a Second & 16 & 7.0 \\
Language & & \\
Bilingual Bicultural & 10 & 4.3 \\
Education & & \\
\hline
\end{tabular}

Further analysis of the demographic data showed that 144 of the 230 participants (62.6\%) had previous field or practicum experience, while 86 (37.4\%) had no previous field or practicum experience. The majority of the participants with previous practicum experience were in inclusive classrooms (47.4\%) and 62 participants indicated that there was a child with EBD in the classroom. Those participants familiar with a child diagnosed with EBD (42.2\%), encountered these children in the classroom (33\%) or in another setting (21\%) such as baby sitting or summer camps. Participants also indicated having a relative $(5.7 \%)$ or sibling $(4.3 \%)$ diagnosed with EBD. One hundred and forty participants (60.9\%) had already taken coursework related to EBD. Table 5 depicts the distribution of the groups examined in this study. 
Table 5

Group distributions

\begin{tabular}{lll}
\hline & Frequency & Percentage \\
\hline Field Experience & & \\
Yes & 144 & 62.6 \\
No & 86 & 37.4 \\
Total & 230 & 100 \\
Type of Classroom & & \\
Inclusive & 109 & 47.4 \\
Special Education & 23 & 10.0 \\
Total & 132 & 57.4 \\
Student with EBD in & & \\
classroom & & \\
Yes & 62 & 27.0 \\
No & 60 & 26.1 \\
Total & 122 & 53.0 \\
Familiarity & & \\
Yes & 97 & 42.2 \\
No & 133 & 57.8 \\
Total & 230 & 100 \\
Coursework & & \\
Yes & 140 & 60.9 \\
No & 90 & 39.1 \\
Total & 230 & 100 \\
\hline
\end{tabular}

Scores on the Knowledge of EBD questionnaire

Upon analysis of participants' total knowledge score, it was discovered that the majority of participants scored 4-9 out of the 15 questions correct with a mean score of $6.22(S D=1.52)$. Nine persons scored below 4 points and two persons obtained the highest score of 10 points. See Figure 2 for the distribution of the total knowledge scores. 


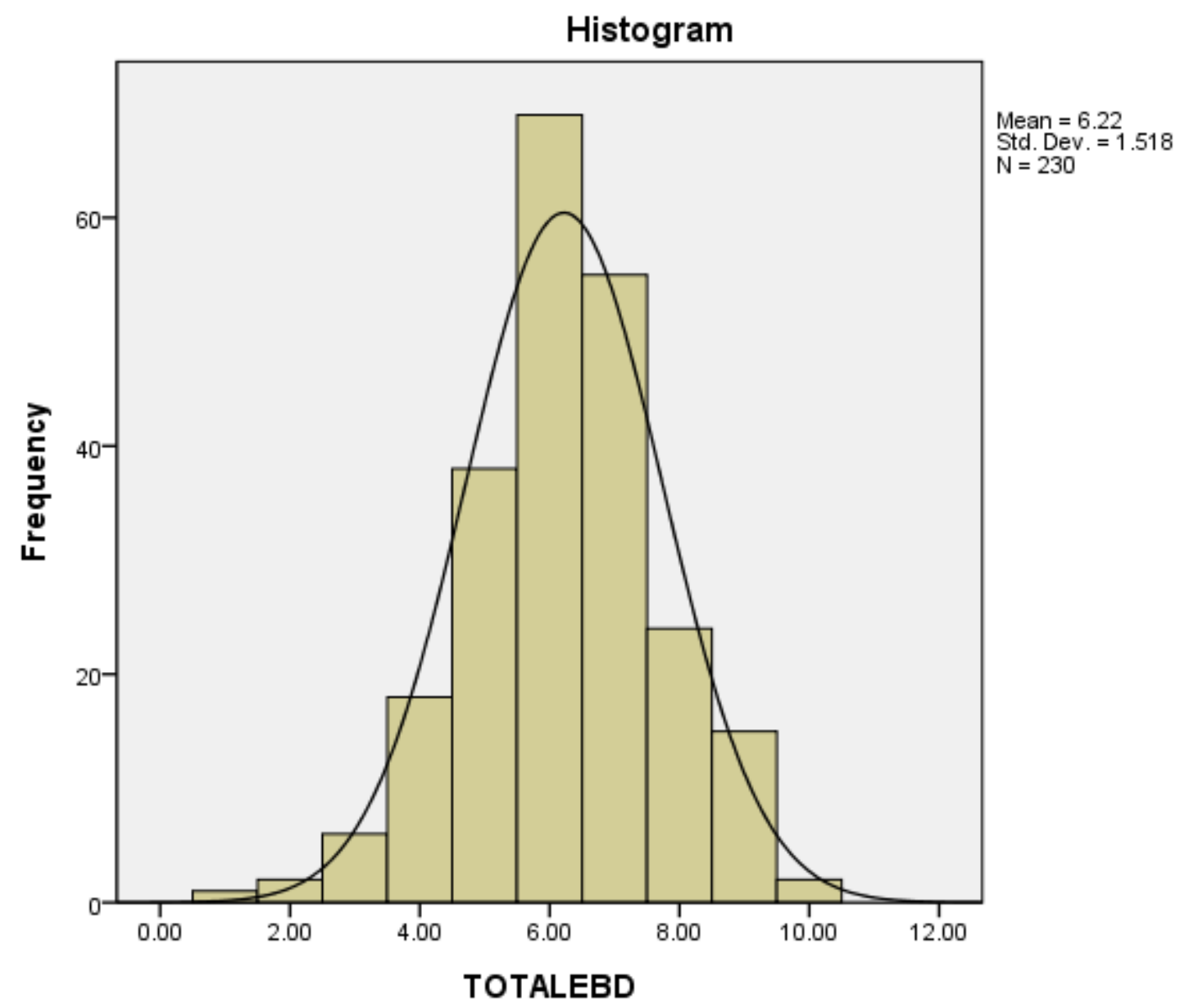

Figure 2.Total knowledge score

\section{Scores on the Teacher Sense} of Efficacy Scale

The majority of the preservice teachers reported high efficacy in their abilities to develop and administer instructional strategies in the classroom, based on the frequency distribution of their responses on the efficacy in instructional strategies subscale. Figure 3 shows the frequency distribution for the efficacy in instructional strategies subscale. 


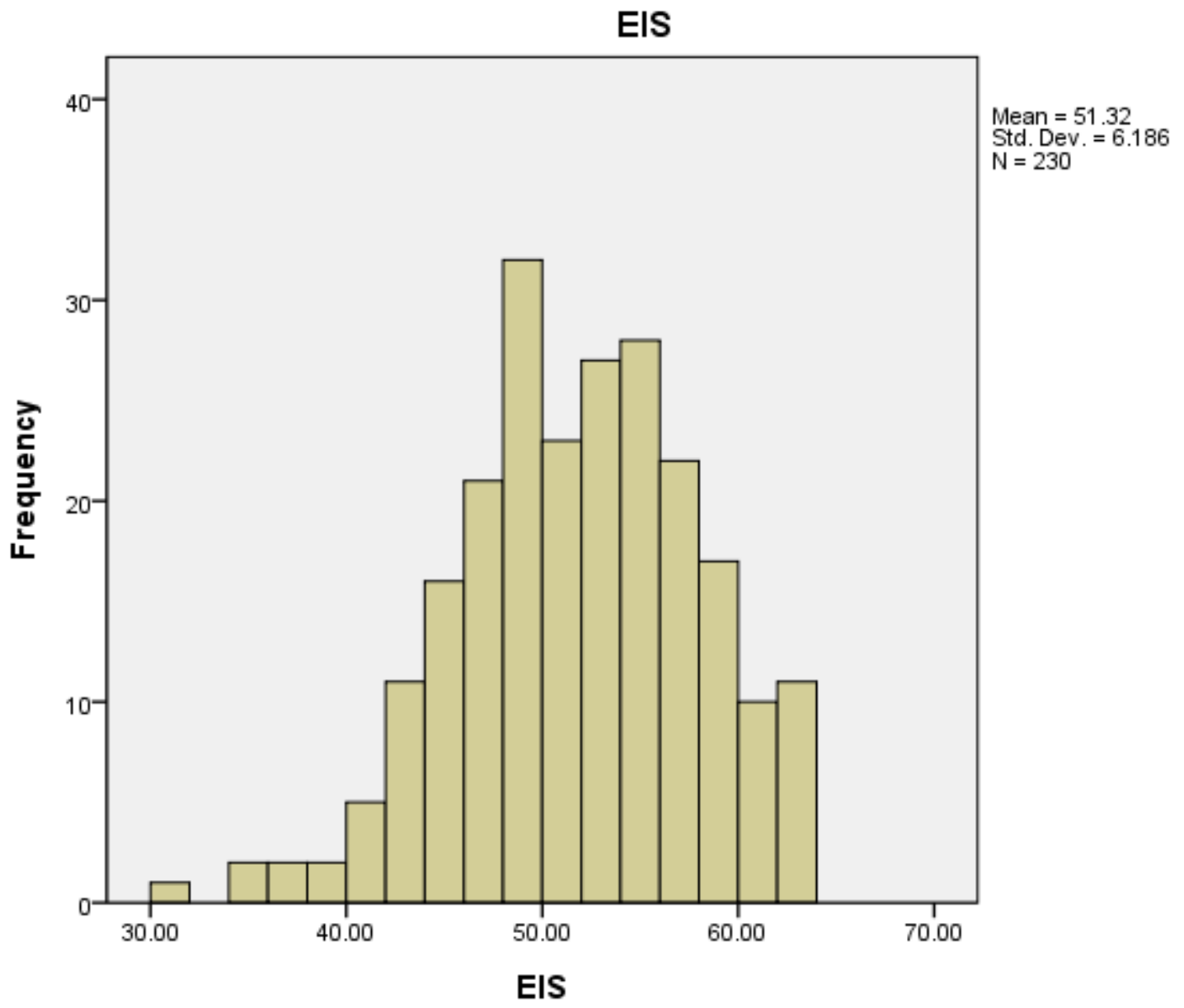

Figure 3. Efficacy in Instructional Strategies Subscale

The participants' responses on the efficacy in classroom management subscale showed that majority of the preservice teachers had high efficacy in their abilities to successfully manage disruptive behavior in the classroom. Participants believed they had quite a bit or a great deal of influence in controlling students' disruptive behavior. The frequency distribution for the efficacy in classroom management subscale is depicted in Figure 4. 


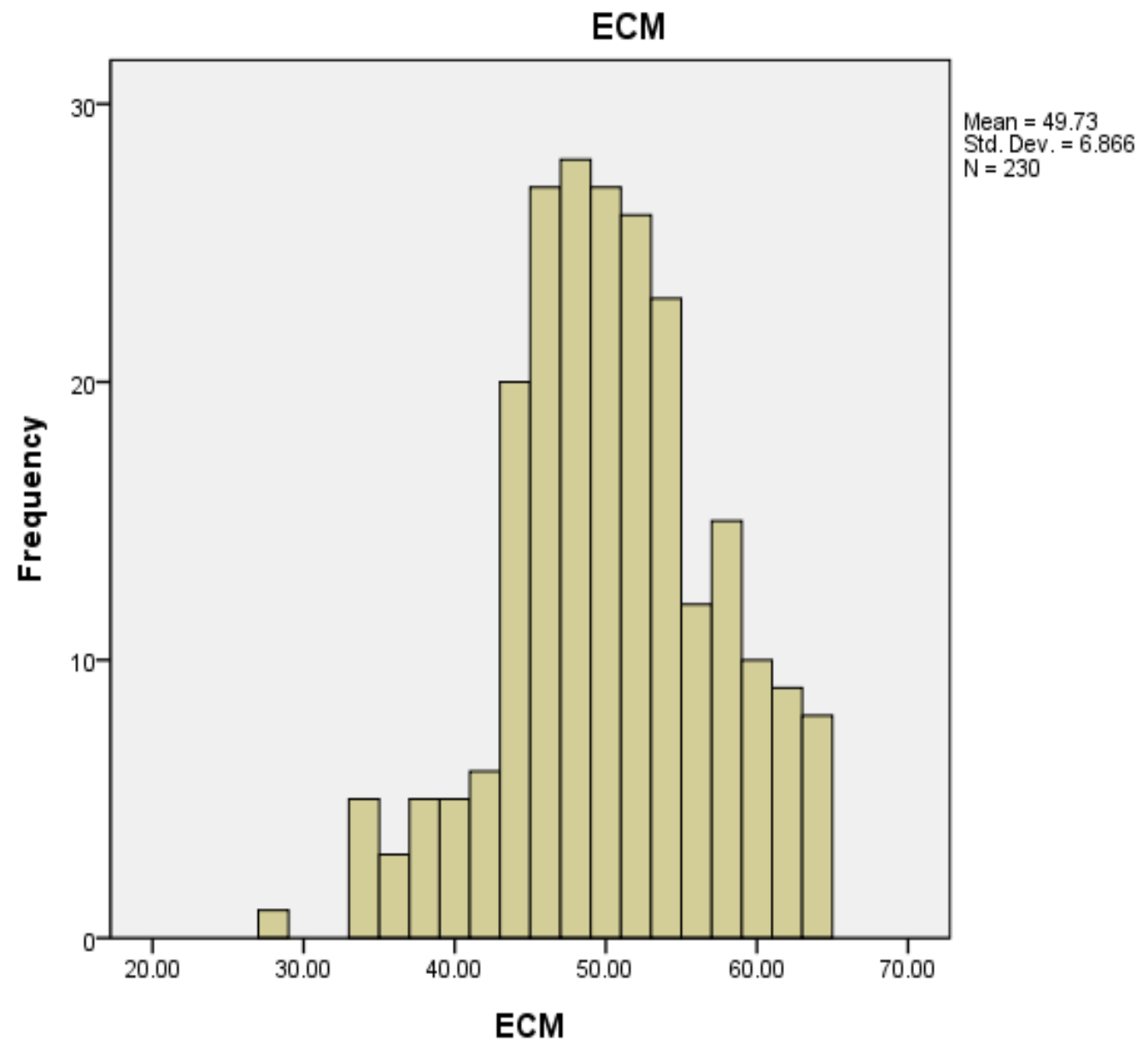

Figure 4. Efficacy in Classroom Management Subscale

Frequency distribution of participants' responses on the efficacy in student engagement subscale showed participants' beliefs in their ability to increase students' motivation to learn and to help students value learning is spread out across the scale. Some participants indicated having some influence, while others believed they had a great deal of influence, and the majority believed they had quite a bit of influence in engaging students in the classroom. Figure 5 shows the frequency distribution for the efficacy in student engagement subscale. 


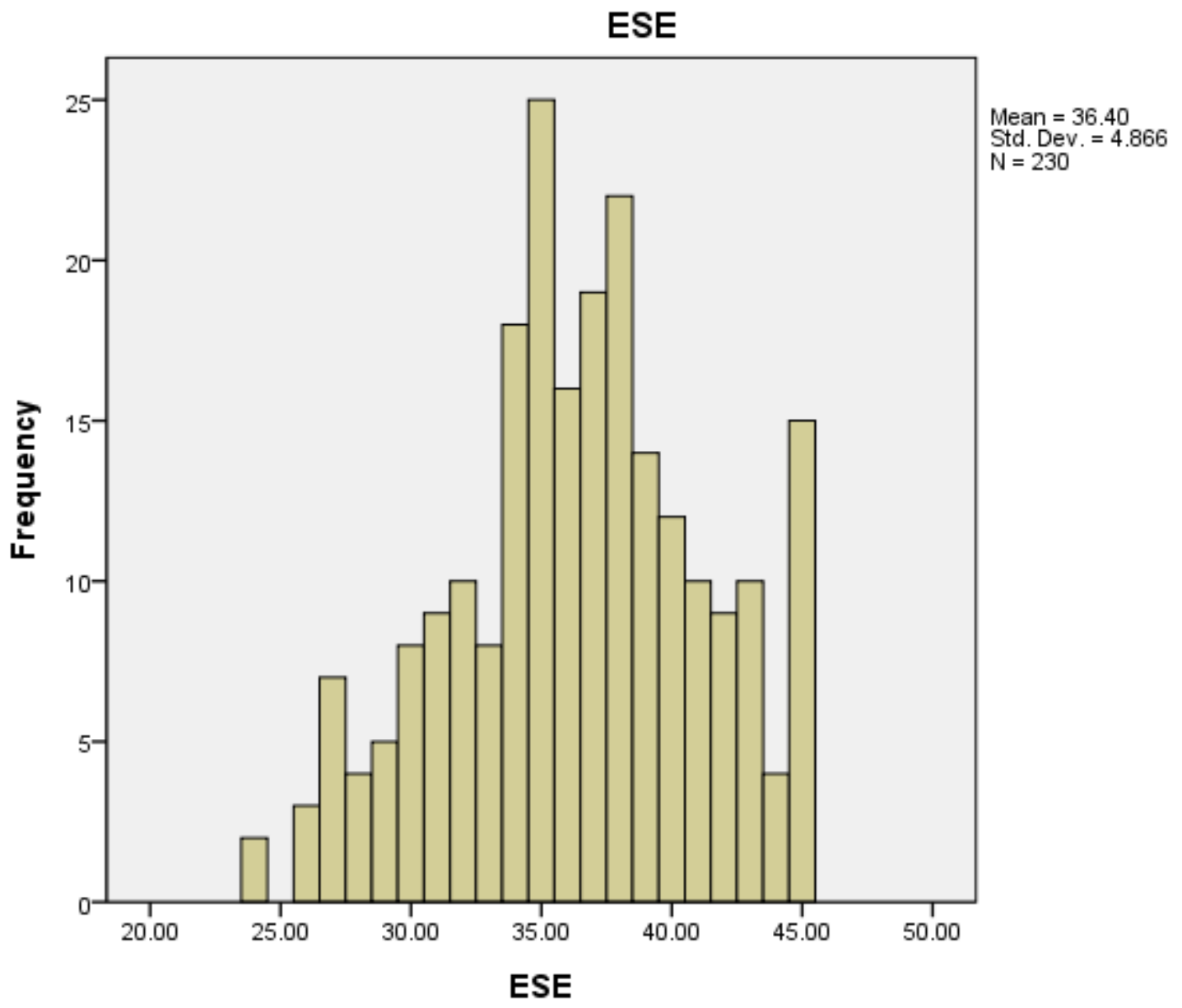

Figure 5. Efficacy in Student Engagement Subscale

The majority of participants indicated having high efficacy in their abilities on the efficacy in instructional abilities subscale. These participants believed they had quite a bit or a great deal of ability in successfully instructing students. The frequency distribution for the efficacy in instructional abilities subscale is displayed in Figure 6. 


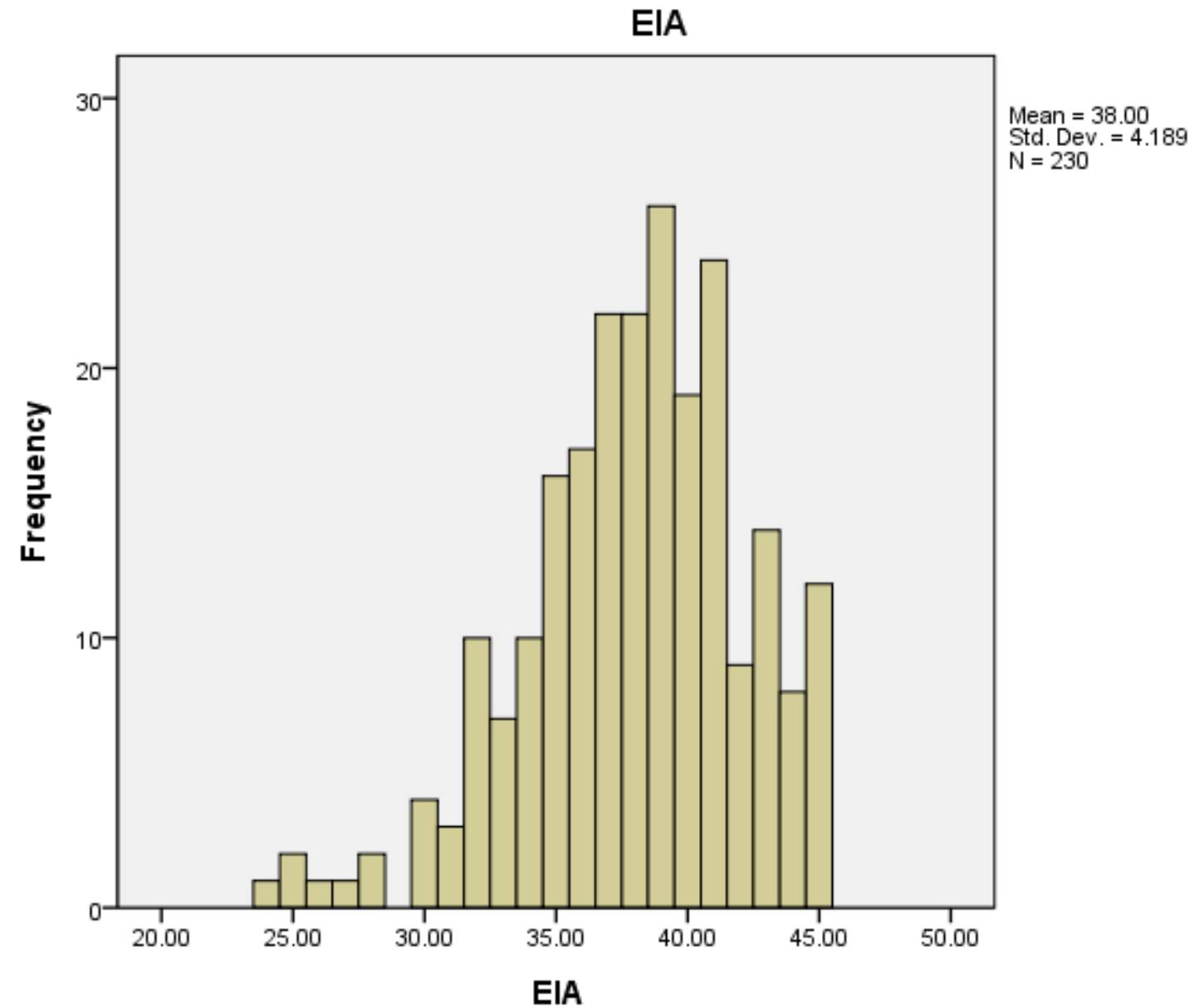

Figure 6. Efficacy in Instructional Ability Subscale

\section{Results of the Inferential}

\section{Statistics Analyses}

In comparing those participants who had previous field experience $(M=6.21$, $S D=1.44)$ and those who had no previous field experience $(M=6.24, S D=1.64)$ on their total knowledge of EBD scores, the $t$-test showed that there is no statistically significant difference between the group means $t(228)=-.173, p=.863$. This represented a smallsize effect, Cohen's $d=-.023$. 
The results of the $t$-test comparing participants who were familiar with a child diagnosed with $\operatorname{EBD}(M=6.12, S D=1.39)$ against those who were non-familiar $(M=6.29$, $S D=1.60$ ), showed no statistically significant difference between the two group means $t$ $(228)=-.836, p=.404$. This represented a small size effect, Cohen's $d=-.11$.

Additionally, the $t$-test revealed no statistically significant difference between the group means of those who had previous coursework $(M=6.12, S D=1.48)$ and those who no previous coursework $(M=6.38, S D=1.56), t(228)=-1.251, p=.212$. This represented a small size effect, Cohen's $d=-.17$.

Subsequently, a discriminant analysis was conducted using the variable field experience and either the multiple choice or true and false questions, to determine which question type best discriminated between those participants who had previous field experience and those who had no previous field experience. The discriminant analysis revealed one discriminant function. This function explained $100 \%$ of the variance, canonical $\mathrm{R}^{2}=.005$. The discriminant function was not able to significantly differentiate between those who had previous field experience and those who had no previous field experience, $\Lambda=.929, \chi^{2}(2)=1.040, p=.594$.

A MANOVA was conducted to evaluate whether there were any differences among preservice teachers in their self efficacy and knowledge of EBD based on their university classification. There was a significant effect of university classification on participants' self efficacy using Wilks' statistic, $\Lambda=.891, F(15,613.3)=1.75, p=.039$. The separate univariate analysis revealed a significant difference in university classification on the efficacy in instructional strategies subscale, $F(3,223)=1.128$, $p=.029$ and efficacy in instructional ability subscale, $F(3,223)=1.228, p=.023$. 
The contrasts table showed that the significant difference occurred between juniors and graduates on both their efficacy in instructional strategies $(p=.043)$ and efficacy in instructional abilities $(p=.016)$ subscales. There is a $95 \%$ confidence that this difference is meaningful. See Table 6 for the contrast table on the efficacy subscales. Level 1 refers to sophomores, Level 2- juniors, Level 3- seniors and Level 4- graduate students.

Table 6

Contrast Tables on the TSES subscales

\begin{tabular}{|c|c|c|c|c|}
\hline \multicolumn{3}{|c|}{ CLASSIFICATION Simple Contrast } & \multicolumn{2}{|c|}{ Dependent Variable } \\
\hline & & & EIS & ECM \\
\hline \multirow[t]{5}{*}{ Level 1 vs. Level 4} & \multicolumn{2}{|l|}{ Contrast Estimate } & .830 & 2.054 \\
\hline & \multicolumn{2}{|l|}{ Std. Error } & 2.369 & 2.662 \\
\hline & \multicolumn{2}{|l|}{ Sig. } & .726 & .441 \\
\hline & 95\% Confidence Interval & Lower Bound & -3.838 & -3.191 \\
\hline & for Difference & Upper Bound & 5.498 & 7.300 \\
\hline \multirow[t]{5}{*}{ Level 2 vs. Level 4} & \multicolumn{2}{|l|}{ Contrast Estimate } & -2.584 & -1.891 \\
\hline & \multicolumn{2}{|l|}{ Std. Error } & 1.268 & 1.425 \\
\hline & \multicolumn{2}{|l|}{ Sig. } & .043 & .186 \\
\hline & \multirow{2}{*}{$\begin{array}{l}95 \% \text { Confidence Interval } \\
\text { for Difference }\end{array}$} & Lower Bound & -5.084 & -4.699 \\
\hline & & Upper Bound & -.085 & .918 \\
\hline \multirow[t]{8}{*}{ Level 3 vs. Level 4} & \multicolumn{2}{|l|}{ Contrast Estimate } & .253 & -1.257 \\
\hline & \multirow{6}{*}{$\begin{array}{l}\text { Std. Error } \\
\text { Sig. } \\
95 \% \text { Confidence Interval } \\
\text { for Difference }\end{array}$} & & 1.118 & 1.257 \\
\hline & & & .821 & .318 \\
\hline & & Lower Bound & -1.951 & -3.733 \\
\hline & & Upper Bound & 2.457 & 1.219 \\
\hline & & & \multicolumn{2}{|c|}{ Dependent Variable } \\
\hline & & & $\overline{\mathrm{ESE}}$ & EIA \\
\hline & \multicolumn{2}{|l|}{ Contrast Estimate } & 2.686 & .010 \\
\hline \multirow[t]{5}{*}{ Level 1 vs. Level 4} & \multicolumn{2}{|l|}{ Std. Error } & 1.882 & 1.603 \\
\hline & Sig. & & .155 & .995 \\
\hline & \multirow{2}{*}{$\begin{array}{l}95 \% \text { Confidence Interval } \\
\text { for Difference }\end{array}$} & Lower Bound & -1.023 & -3.149 \\
\hline & & Upper Bound & 6.395 & 3.168 \\
\hline & \multirow{2}{*}{\multicolumn{2}{|c|}{$\begin{array}{l}\text { Contrast Estimate } \\
\text { Std. Error }\end{array}$}} & -.985 & -2.089 \\
\hline \multirow[t]{5}{*}{ Level 2 vs. Level 4} & & & 1.008 & .858 \\
\hline & \multicolumn{2}{|l|}{ Sig. } & .329 & .016 \\
\hline & 95\% Confidence Interval & Lower Bound & -2.971 & -3.780 \\
\hline & for Difference & Upper Bound & 1.001 & -.398 \\
\hline & \multirow{5}{*}{$\begin{array}{l}\text { Contrast Estimate } \\
\text { Std. Error } \\
\text { Sig. } \\
95 \% \text { Confidence Interval } \\
\text { for Difference }\end{array}$} & & -.024 & -.187 \\
\hline \multirow[t]{4}{*}{ Level 3 vs. Level 4} & & & .889 & .757 \\
\hline & & & .978 & .805 \\
\hline & & Lower Bound & -1.775 & -1.678 \\
\hline & & Upper Bound & 1.727 & 1.304 \\
\hline
\end{tabular}


Additionally, the results of the MANOVA showed that there was a significant effect of university classification on participants' knowledge of EBD, using Wilks' statistic, $\Lambda=.901, F(6,440)=3.92, p=.001$. The separate univariate analysis revealed a significant difference of university classification on both the multiple choice items, $F(3,221)=5.275, p=.002$, and the true and false items, $F(2,221)=3.085, p=.028$. The MANOVA was followed up by a discriminant analysis, which revealed two discriminant functions. The first function explained $99.5 \%$ of the variance, canonical $\mathrm{R}^{2}=.09$. In combination, the two functions significantly differentiated between the university classifications, $\Lambda=.901, \chi^{2}(6)=23.037, p=.001$. The discriminant function discriminates the graduates from the juniors.

\section{Answers to the Research Questions}

Research question 1. To what extent does personal experience, field experience, coursework, and knowledge of EBD predict preservice teachers' self efficacy?

A MANOVA was used to identify the effect of knowledge of EBD, familiarity with a child with EBD, and previous field experience and coursework, on the participants' scores on the self efficacy subscales. The results of the analysis show based on Wilk's statistic, there was no significant effect of field experience on the self efficacy scales endorsed $(\Lambda=.995), F(5,218)=.203, p>.05$. When compared based on familiarity with a child with EBD, Wilk's statistic showed there was no significant effect on the self efficacy scales $(\Lambda=.981), F(5,218)=.854, p>.05$. Additionally, there was no significant effect of previous coursework on the self efficacy scales endorsed $(\Lambda=$ $.995), F(5,218)=.228, p>.05$. 
Hence, there were no group differences in the endorsement of items related to the TSES subscales. Also, evaluation of the univariate tests further confirmed that past field experience, previous coursework, familiarity with a child with EBD, and knowledge of EBD had no effect on the efficacy scales endorsed. See Table 7 for the distribution of the multivariate tests.

Table 7

Multivariate Tests

\begin{tabular}{|c|c|c|c|c|}
\hline Effect & & Value & $\mathrm{F}$ & Sig. \\
\hline Field experience & Wilks' Lambda & .995 & $.203^{\mathrm{a}}$ & .961 \\
\hline Familiarity & Wilks' Lambda & .981 & $.854^{\mathrm{a}}$ & .513 \\
\hline Coursework & Wilks' Lambda & .995 & $.228^{\mathrm{a}}$ & .950 \\
\hline $\begin{array}{l}\text { Field experience } \\
\text { *familiarity }^{\text {famila }}\end{array}$ & Wilks' Lambda & .962 & $1.737^{\mathrm{a}}$ & .127 \\
\hline $\begin{array}{l}\text { Field experience } \\
* \text { coursework }\end{array}$ & Wilks' Lambda & 993 & $.287^{\mathrm{a}}$ & .920 \\
\hline Familiarity*coursework & Wilks' Lambda & 983 & $.735^{\mathrm{a}}$ & .598 \\
\hline $\begin{array}{l}\text { Field experience * } \\
\text { familiarity* coursework }\end{array}$ & Wilks' Lambda & .977 & $1.048^{\mathrm{a}}$ & .390 \\
\hline
\end{tabular}

Research Question 2. Are there any differences among special education and general education teacher programs with regards to knowledge of emotional and behavioral disorders?

In order to identify any differences between the general education programs and the special education teacher program and their knowledge of EBD score, a one way ANOVA was conducted. 
The results of the ANOVA indicate no statistically significant difference among the groups on their knowledge of $\mathrm{EBD}, F(3,223)=.136, p=.939$. See Table 8 for the ANOVA Table.

Table 8

ANOVA Table

\begin{tabular}{lllll}
\hline Source & Sum of Squares & DF & Mean Square & $\mathrm{F}^{*}$ \\
\hline Between & .942 & 3 & .314 & .136 \\
Within & 515.481 & 223 & 2.312 & \\
Total & 516.423 & 226 & & \\
\hline
\end{tabular}

The mean distribution of the different teacher education programs based on the Knowledge of EBD scores show that Elementary and Secondary programs had similar means, Special Education had the lowest mean, and Post Baccalaureate had the highest mean by comparison.

Research Question 3. Are there any differences in preservice teachers' knowledge of EBD and self efficacy across the different teacher education programs?

A MANOVA was conducted to evaluate whether there were any differences among elementary, secondary, post baccalaureate, and special education preservice teachers in their self efficacy and knowledge of EBD. Using Wilks' statistic, there was no significant effect of type of program on respondents self efficacy $\Lambda=.947$, $F(15,604.9)=.808, p=.67$. However, the separate univariate analysis revealed a significant difference in the type of program on the efficacy in instructional strategies subscale, $F(3,223)=3.003, p=.031$. 
Additionally, the results of the MANOVA revealed that teacher education program had a significant effect on participants' knowledge of EBD, based on Wilks' statistic, $\Lambda=.929, F(6,434)=2.728, p=.013$. The separate univariate analysis revealed a significant difference of teacher education program on both the multiple choice items, $F(3,218)=3.045, p=.03$, and the true and false items, $F(3,218)=2.757, p=.043$. The MANOVA was followed up by a discriminant analysis, which revealed two discriminant functions. The first function explained $94.4 \%$ of the variance, canonical $\mathrm{R}^{2}=.07$. In combination, the two functions significantly differentiated between the teacher education programs, $\Lambda=.929, \chi^{2}(6)=16.141, p=.013$. The discriminant function discriminates the post baccalaureate from the special education teacher programs.

Research Question 4. Does practicum experience and exposure to a student diagnosed with EBD during the practicum experience influence preservice teachers' efficacy in student engagement?

In order to answer whether practicum experience and exposure to a student diagnosed with EBD during the practicum experience had an influence on participants' efficacy in student engagement, two separate $t$-tests were conducted.

The results of the $t$-test comparing participants who had previous practicum experience $(M=36.48, S D=5.03)$ against those who had no practicum experience $(M=$ 36.26, $S D=4.60$ ), revealed no statistically significant difference between the two group means $t(228)=-.347, p=.729$. This represented a small size effect, Cohen's $d=-.046$. 
In comparing participants who had a student diagnosed with EBD in the classroom $(M=37.02, S D=4.81)$ against those who had no student with EBD in the classroom $(M=35.62, S D=5.39)$, the $t$-test showed no statistically significant difference between the two group means $t(120)=1.514, p=.133$. This represented a small size effect, Cohen's $d=.28$.

\section{Summary}

This chapter provides an outline of the findings of the study. A description of the participants in the study was first presented. Study participants were 230 preservice teachers from various teacher education programs. Participants varied in whether they had previous field experience, were familiar with a child diagnosed with EBD, and whether they had taken any previous coursework related to EBD. Three hundred teacher candidates were invited to participate in this study but only 230 completed the surveys giving a response rate of $76.7 \%$.

Additionally, the participants' responses on the survey instruments and the answers to the research questions were provided. Participants received on average 4-9 points on the Knowledge of EBD measure with only two persons receiving the highest score of 10 points. The preservice teachers had overall high self efficacy. There was no statistically significant difference on the knowledge of EBD scores between those participants who had previous field experience, previous coursework, and were familiar with students with EBD and those participants who had none of those experiences. There was a significant effect of university classification on participants' self efficacy and knowledge of EBD scores. 
The results of the analysis showed no significant effect of previous field experience, previous coursework, familiarity with a child diagnosed with EBD, and knowledge of EBD on participants' self efficacy. There were no significant differences found between general education and special education preservice teachers on their self efficacy and knowledge of EBD. However, a significant difference was found among the programs on the efficacy in instructional strategies subscale. Also, across teacher education programs, there was a significant difference between those participants in the post baccalaureate and special education programs. Additionally, there was no significant effect of practicum experience and having a student with EBD in the classroom on preservice teachers' efficacy in student engagement. 


\section{CHAPTER V DISCUSSION}

This chapter provides a summary of the purpose of the study, and highlights the findings. An interpretation of the findings and implications for practice is also included. Additionally, the limitations of the study and the areas for future research are presented. This chapter is divided into five sections, (a) summary of the purpose of the study, (b) discussion of the findings, (c) conclusion, (d) limitations of the study, and (e) future research.

\section{Summary of the Purpose of the Study}

This research aimed to discover preservice teachers' sense of teaching efficacy and knowledge of EBD prior to their student teaching. It was important to determine the extent of preservice teachers' knowledge of EBD and their overall beliefs in their ability to successfully engage, manage, and instruct students diagnosed with emotional and behavioral disorders.

Additionally, the purpose of this research was to answer the following questions:

Q1 To what extent does personal experience, field experience, coursework, and knowledge of EBD predict preservice teachers' self efficacy? (Main \& Hammond, 2008)

Q2 Are there any differences among special education and general education teacher programs with regards to knowledge of emotional and behavioral disorders? (Manning et al., 2009) 
Q3 Are there any differences in preservice teachers' knowledge of EBD and self efficacy across the different teacher education programs? (Billingsley, 2004)

Q4 Does practicum experience and exposure to a student diagnosed with EBD during the practicum experience influence preservice teachers' efficacy in student engagement? (D’Alonzo et al., 1996)

To answer these research questions descriptive and inferential statistics were conducted. Participants' scores on the self efficacy subscales (i.e., instructional strategies, student engagement, classroom management, and instructional ability) were explored. Additionally, participants' scores on the knowledge of EBD measure were examined. These scores were used in the analysis to better understand the nature of teacher education programs, and to identify whether preservice teachers are adequately prepared to work with students diagnosed with EBD in their diverse classrooms.

\section{Discussion of the Findings}

This research included 230 participants who varied in whether they had previous field experience or coursework, and were familiar with a child diagnosed with EBD. The majority of the participants with previous field experience were in inclusive classrooms, and of these participants $(27 \%)$ there was a child diagnosed with EBD present in that classroom. Thus, some preservice teachers may have received authentic experiences, whereby they engaged with students with EBD in their field placement but others may have not. Furthermore, many participants indicated that often they were not aware of whether or not there were any students diagnosed with EBD present in the classroom. Also, those who were made aware of the presence of students with EBD in the classroom were unsure of the type of diagnosis. This lack of awareness suggest that preservice teachers are not receiving adequate exposure to students with EBD in their field 
experiences and are missing out on opportunities to learn strategies for identifying, managing, and instructing students with EBD. This discovery partially supports the notion proposed by D’Alonzo et al. (1996) that general education teachers have little or no preparation in educating students with disabilities.

Participants' scores on the knowledge of EBD questionnaire revealed that the preservice teachers had reasonable knowledge of EBD. There were only two participants who got the highest score of 10 out of a possible 15 , and the majority of participants received 4-9 questions correct. Additionally, the results of the study revealed that there were no statistically significant differences between those participants who had previous field experience, who were familiar with a child with EBD, and had previous coursework and those who had none of those experiences. However, there was a significant difference between juniors and graduates in their knowledge of EBD. This suggests that the graduate students' additional experiences may have contributed to their added knowledge of EBD. Hence, these results indicate that participants received their information about EBD from various resources, and the nature of teacher preparation programs does not provide preservice teachers with adequate information about students with emotional and behavioral disorders. Subsequently, the results support the difficulty identified by Manning et al. (2009) that teacher preparation programs are finding it impossible to include all the items on the Council for Exceptional Children's list of the minimum knowledge, skills, and dispositions needed by teachers for effectively working with students with EBD in their coursework.

Overall, the participants in the study had high efficacy in their abilities to instruct, manage, and engage students in the classroom. The majority of participants had high efficacy in their ability to develop and administer instructional strategies, and their ability 
to successfully manage disruptive behaviors in the classroom. However, participants believed that they had either quite a bit influence or great deal of influence in successfully engaging or instructing students. The overall high sense of efficacy of the participants in this study supports Main and Hammond (2008) finding that preservice teachers have generally a high sense of efficacy.

Tschannen-Moran and Woolfolk-Hoy (2007) found that experienced teachers show higher efficacy beliefs in classroom management and instructional strategies than in student engagement. The results of this current study show that preservice teachers also have higher efficacy beliefs in their abilities to manage and instruct students than in their abilities to engage students. Consequently, these findings suggest that teachers are receiving more experiences and instruction with regards to managing and instructing students with disabilities but not strategies in successfully engaging students with disabilities.

Furthermore, participants differed significantly in their self efficacy when compared across university classifications. There was a significant difference between juniors and graduates in their efficacy in instructional strategies and instructional abilities. However, there was no difference in participants' efficacy in student engagement and classroom management when compared by university classification. These findings suggest that the graduate preservice teachers' additional experiences influenced their beliefs in their ability to develop and administer instructional strategies in the classroom. Moreover, these differences further highlight that teacher candidates are receiving more experiences related to instructional strategies than student engagement. Hence, as preservice teachers continue their education they receive more 
knowledge about developing strategies for helping students to learn the class material but not in successfully engaging the students. Seemingly, the belief in managing and engaging students remains constant despite the increase in knowledge and experience.

Research question 1. To what extent does personal experience, field experience, coursework, and knowledge of EBD predict preservice teachers' self efficacy?

There was no statistically significant difference between participants who had previous field experience and those who had no past field experience on the self efficacy scales endorsed. There was also no statistically significant difference in self efficacy between those who had previous coursework and those who had no coursework. Additionally, there was no statistically significant difference between participants who were familiar with a child diagnosed with EBD and those not familiar with a child diagnosed with EBD on the self efficacy scales endorsed.

Therefore, the results show that field experience, related coursework, familiarity with a child diagnosed with EBD, and knowledge of EBD had no significant effect on preservice teachers' self efficacy. As previously stated, the preservice teachers had an overall high sense of efficacy in their abilities to instruct, manage, and engage students. Hence, the teacher candidates' different experiences did not have a significant impact on their self efficacy. Gurvitch and Metzler (2008) suggested that if preservice teachers received authentic field experiences that strengthened their abilities in the classroom, their self efficacy beliefs would increase. Authentic field experiences allow the preservice teachers to be engaged in their learning and make the experience meaningful to their development as teachers. These authentic experiences include demonstrating competency in a real classroom setting by successfully engaging students, and implementing strategies for managing and instructing students. 
Thus, it can be inferred that preservice teachers' field experiences may not be providing the authentic experiences needed to further increase their self efficacy beliefs. The preservice teachers' sense of efficacy may be a direct result of their personal sense of efficacy, and their teacher preparation courses and experiences may not be positively contributing to the beliefs in their abilities to successfully instruct, manage, and engage students. However, as previously shown, the teacher candidates have higher beliefs in their abilities to instruct and manage students, but not in engaging and providing students with rich learning experiences.

Interestingly, the preservice teachers' knowledge of EBD also had no effect on their self efficacy beliefs. It was believed that increased knowledge would increase participants' self efficacy as proposed by Swackhamer et al. (2009). However, it can be inferred that the preservice teachers already possessed high self efficacy; thus, additional coursework did not make a significant difference on their self efficacy. Furthermore, this lack of influence of additional knowledge on preservice teachers' self efficacy is confirmed by the relatively low scores on the knowledge of EBD questionnaire received by participants, and the presence of no significant difference between those participants who had previous coursework and those who had none.

Subsequently, in order for knowledge of EBD, additional coursework, field experiences, and familiarity with a child with EBD to have a significant impact on preservice teachers' self efficacy, they should be engaged in mastery experiences. In these situations, the preservice teachers are encouraged to implement strategies with the assistance of a coach. This will help to ensure the preservice teachers attain success in the classroom (Tschannen-Moran \& McMaster, 2009). 
Research Question 2. Are there any differences among special education and general education teacher programs with regards to knowledge of emotional and behavioral disorders?

The three general education teacher programs, elementary, secondary, and post baccalaureate, were compared with the special education program. The mean distribution showed that the post baccalaureate program had the highest means while special education had the lowest mean, and the elementary and secondary programs had similar means. However, these differences in the means were non-significant. There is no statistically significant difference among the special education and general education preservice teachers on their knowledge of EBD.

According to Manning et al. (2009), the Council for Exceptional Children established a list of the minimum knowledge, skills, and dispositions needed by special education teachers for effectively working with students with EBD and this list is being used by general teacher education programs. However, since there was no difference between the special education and general education preservice teachers in this study on their knowledge of EBD, this further confirms the difficulty faced in successfully implementing the entire list in teacher preparation coursework.

Research Question 3. Are there any differences in preservice teachers' knowledge of EBD and self efficacy across the different teacher education programs? There was no statistically significant difference in participants' self efficacy across the different teacher education programs. The only significant difference was found on the efficacy in instructional strategies subscale. It was expected that special education teachers would have lower self efficacy than the general education teachers (Billingsley, 2004) and that the elementary preservice teachers would have higher 
efficacy in classroom management than the secondary preservice teachers (Klassen \& Chiu, 2010). However, this lack of differences further indicate that the preservice teachers have an overall high sense of belief in their abilities in the classroom, and distinctions among teachers in their efficacy are established after years of experience in the classroom. Klassen and Chiu (2010) found that efficacy in classroom management, student engagement, and instructional strategies increased with years of experience in teaching.

Furthermore, a significant difference among the teacher education programs on the efficacy in instructional strategies subscale is in line with previous findings that preservice teachers have higher efficacy beliefs in instructional strategies (TschannenMoran \& Woolfolk-Hoy, 2007). Subsequently, the participants' consistent difference in their efficacy in instructional strategies may be attributed to greater emphasis in teacher education programs in preparing preservice teachers for instructing and not for engaging students.

Additionally, there was a significant difference among the teacher education programs on the participants' scores on their knowledge of EBD. The significant difference was found between the post baccalaureate and special education programs. This significant difference suggests that the special education teachers may be receiving more information about EBD than the elementary and secondary teachers, while the additional experiences of those in the post baccalaureate programs are providing them with more information about emotional and behavioral disorders. These findings further support the notion that general education teachers have little or no preparation in educating students with disabilities. They often leave the education of students with disabilities to those teachers who are trained to do so (D'Alonzo et al., 1996). 
Research Question 4. Does practicum experience and exposure to a student diagnosed with EBD during the practicum experience influence preservice teachers' efficacy in student engagement?

A comparison of the participants who had previous practicum experience and those who had no previous practicum experience revealed no statistically significant difference between the two groups on their efficacy in student engagement. There was also no statistically significant difference between those participants who had a student diagnosed with EBD in their practicum classroom and those who had no students with EBD in the classroom. Therefore, practicum experience and having a student diagnosed with $\mathrm{EBD}$ in the practicum classroom had no influence on the participants' efficacy in student engagement.

It was expected that factors such as experience working with a student with disability, and preservice training would influence preservice teachers' beliefs in their abilities to successfully engage students in a classroom (D’Alonzo et al., 1996; Jeon \& Peterson, 2003). However, the results of this study suggest that though participants may have been aware of the presence of the student with a disability in the classroom, there may have been no opportunities to interact with these students in the classroom. Also, the preservice teachers may have not observed the teachers motivating these students to learn. Thus, the practicum experience may have failed to provide the preservice teachers with authentic field experiences, and the opportunity to have positive experiences with students with emotional and behavioral disorders. Thereby, the practicum experience failed to influence the preservice teachers' beliefs in their ability to successfully help students to value learning (Woolfson, \& Brady, 2009). 


\section{Conclusion}

This research aimed to discover preservice teachers' sense of efficacy and their knowledge of emotional and behavioral disorders. The results of the study show that overall participants had high efficacy in their ability to instruct, engage, and manage students. The participants had higher efficacy in instructional strategies and classroom management than in student engagement. Additionally, there were significant differences in the efficacy in instructional strategies across teacher education programs, specifically between juniors and graduates. The results of the study show that teacher candidates receive more experiences that influence their beliefs in developing and implementing instruction in the classroom. However, more emphasis should be placed on providing preservice teachers with strategies for increasing students' motivation and for helping students to learn. Moreover, positive interactions with students with emotional and behavioral disorders are necessary for helping these students to be successful in school. Also, positive teacher- student interactions decreases teachers' stress levels and enhances teachers' self efficacy (Furlong et al., 2004).

Additionally, the results of the study show that practicum experience and having a child diagnosed with EBD in the classroom had no influence on the preservice teachers' efficacy in student engagement. Furthermore, the results demonstrate that field experiences, additional coursework, knowledge of EBD, and familiarity with a child with EBD had no influence on preservice teachers' self efficacy. These results suggest that teacher education programs should place more focus on providing preservice teachers with authentic field experiences, where they are placed in diverse classrooms and are 
given the opportunity to interact with students with EBD. Also, during the field experiences, the classroom teachers should make the teacher candidates aware of the students diagnosed with EBD and the nature of their disorders.

Preservice teachers should also be given the opportunity to observe the proper strategies for not only managing and instructing students with EBD but also proper strategies for motivating these students to learn. As noted by Kamen et al. (2000), teachers believed that teacher preparation programs should focus on proper strategies for including students with disabilities in the classroom. These strategies could be implemented either through the provision of courses focused on integration and strategies, or incorporating these strategies into already existing coursework.

The participants in this study received low scores on their knowledge of EBD. There was a difference in knowledge of EBD across the teacher education programs especially between the special education and post-baccalaureate programs. This difference across teacher education programs further indicates the need to increase the knowledge of emotional and behavioral disorders in general education programs particularly in the elementary and secondary programs. Furthermore, field experiences, familiarity with a child with EBD, and additional coursework had no significant impact on participants' knowledge of EBD. Hence, teacher education programs should make further efforts to ensure preservice teachers receive the necessary knowledge for identifying, instructing, and managing students with emotional and behavioral problems. This additional knowledge will help change teachers' attitudes about working with students with EBD and prepare novice teachers for working with diverse populations in their classrooms (D’Alonzo et al., 1996; Jeon \& Peterson, 2003). 
Hence, based on the findings of this study it can be concluded that overall preservice teachers have high efficacy in their beliefs in their ability to successfully instruct, and manage students with EBD. However, there is a need to enhance their ability to successfully motivate and help these students to learn. The field experiences and coursework which form part of teacher education programs are not enhancing preservice teachers' sense of efficacy or their knowledge of EBD. Accordingly, further efforts should be made to improve preservice teachers' knowledge of EBD and to provide strategies for identifying and working with students with EBD in their classrooms. This will greatly enhance preservice teachers' self efficacy for engaging students and decrease their stress levels; thus, contributing to new teachers staying in the profession after the first year of teaching and improving retention rates.

\section{Limitations}

This research was limited in the amount of information that could be obtained from the preservice teachers about their experiences in the teacher preparation programs and their experiences with emotional and behavioral disorders since a quantitative method was utilized. Hence, additional information about the nature of the practicum experience would have been better obtained through interviews with those students who had previous field experiences.

The moderate response rate and the inability to obtain more participants from the special education program limit the ability to generalize the results of this study to other teacher preparation programs. Moreover, the low reliability of the scores on the Knowledge of EBD questionnaire can be attributed to the lack of variability in participants' responses. Also, since participants received relatively low scores on the 
questionnaire the reliability of those scores was compromised. This low reliability of the scores on the Knowledge of EBD questionnaire further limits the ability to generalize the results of this study to the entire population of teacher candidates.

\section{Future Research}

Future research will focus on further improving the Knowledge of EBD questionnaire through the use of item analysis programs to determine the relative difficulty and ease of the questions. Further research should include more students from the special education program and aim to obtain samples from other general education programs. It would also be important to conduct a longitudinal study with preservice teachers, surveying them at the beginning and end of their programs to examine for any changes in their self efficacy and knowledge of EBD. The research would have to utilize online surveys since it would prove difficult to make direct contact with most teacher candidates after their student teaching.

Furthermore, it would be necessary to explore the nature of teacher candidates' field experiences to determine whether or not they are having authentic experiences and are given the opportunity to attain success in the classroom. This could involve either the use of interviews with the students, or observations of their practicum experiences. Additionally, the significant difference between juniors and graduates on their efficacy in instructional strategies should be further explored.

\section{Summary}

This study aimed to discover the extent of preservice teachers' knowledge of EBD and their beliefs in their ability to successfully manage, instruct, and engage students with EBD in their classrooms. The results of the study show that participants had higher beliefs in their efficacy in instructional strategies, than in their efficacy in student 
engagement, classroom management, and instructional abilities. Additionally, preservice teachers' field experiences, additional coursework, and familiarity with a child diagnosed with EBD had no influence on their knowledge of EBD and self efficacy.

It was recommended that teacher education programs focus more on providing teacher candidates with strategies for successfully engaging and motivating students with EBD. Additionally, preservice teachers should be provided with meaningful field experiences where they observe strategies for successfully instructing, engaging, and managing students with EBD. Future research should include qualitative methods such as interviews with preservice teachers or observations in the classroom to obtain further information about the teacher candidates' field experiences. 


\section{REFERENCES}

American Academy of Child Adolescent Psychiatry (2010). Retrieved from http://www.aacap.org/page.ww?name=Home\&section=root

American Psychiatric Association (2000). Diagnostic and Statistical Manual of Mental Disorders (Revised $4^{\text {th }}$ ed.). Washington, DC: American Psychiatric Association.

Ashton, P.T., \& Webb, R. B. (1986). Making a difference: Teachers' sense of efficacy and student achievement. White plains, NY: Longman Inc.

Bandura, A. (1982). Self efficacy mechanism in human agency. American Psychologist, $37,122-147$.

Bandura, A. (1986). Social foundations of thought and action: A social cognitive theory. Englewood Cliffs, NJ: Prentice-Hall.

Bandura, A. (1989). Human Agency in Social Cognitive Theory. American Psychologist, 44(9), 1175-1184.

Bandura, A. (1992). Exercise of personal agency through the self efficacy mechanism. In R. Schwarzer (Ed). Self efficacy: Thought control of action. (pp. 3-38).

Washington: Hemisphere Publishing Corporation.

Bandura, A. (1993). Perceived Self Efficacy in Cognitive Development and Functioning. Educational Psychology, 28, 117-148. 
Bandura, A. (1997). Self-efficacy: The exercise of control. New York: Freeman

Billingsley, B. S. \&. Cross, L.H. (1992). Predictors of commitment, job satisfaction, and intent to stay in teaching: A comparison of general and special educators. The Journal of Special Education, 25, 453-471.

Billingsley, B. S. (2004). Special education teacher retention and attrition: A critical analysis of the research literature. The Journal of Special Education, 38, 39-55.

Bleicher, R. B. (2007). Nurturing confidence in preservice elementary science teachers. Journal of Science Teacher Education,18, 841-860.doi:10.1007/s10972-007-9076-2

Bradley, R., Henderson, K., \& Monfore, D. A. (2004). A national perspective on children with emotional disorders. Behavior Disorders, 29, 211-223.

Buell, M. J., Hallam, R., Gamel-Mccormick, M., \& Scheer, S. (1999). A survey of general and special education teachers' perceptions and inservice needs concerning inclusion. International Journal of Disability, Development \& Education, 46, 143156. doi:10.1080/103491299100597

Cannon, J. R. \& Scharmann, L. C. (1996). Influence of a cooperative early field experience on preservice elementary teachers' science self-efficacy. Science Education, 80(4), 419-36.

Carleton, L. E., Fitch, J. E, \& Krockover, G. H. (2008). An inservice teacher education program's effect on teacher efficacy and attitudes. The Educational Forum, 72, 4662.

Carrier, S. J. (2009). The effects of outdoor science lessons with elementary school students on preservice teachers' self-efficacy. Journal of Elementary Science Education, 21(2), 35-48. 
Chambers, S. M., \& Hardy, J. C. (2005). Length of time in student teaching: Effects on classroom control orientation and self efficacy beliefs. Educational Research Quarterly, 28(3), 3-9.

Chester, M. D., \& Beaudin, B. Q. (1996). Efficacy Beliefs of Newly Hired Teachers in Urban Schools. American Educational Research Journal, 33(1), 233-257.

Coladarci, T. (1992). Teachers' sense of efficacy and commitment to teaching. The Journal of Experimental Education, 60(4), 323-337.

Cone, N. (2008). Community based service learning as a source of personal self efficacy: Preparing preservice elementary teachers to teach science for diversity. School Science and Mathematics, 109, 20-30.

Cook, B. G. (2001). A comparison of teachers' attitudes toward their included students with mild and severe disabilities. The Journal of Special Education, 34, 203-213.

Cooper, P. (2006). Awareness, understanding and the promotion of educational engagement. Emotional and Behavioral Difficulties, 11, 151-3.

D'Alonzo, B. J., Giordano, G., \& Cross, T. L. (1996). Improving teachers' attitudes through teacher education toward the inclusion of students with disabilities into their classrooms. The Teacher Educator, 31,304-312. doi: $10.1080 / 08878739609555123$

Dembo, M. H., \& Gibson, S. (1985). Teachers' sense of efficacy: An important factor in school improvement. The Elementary School Journal, 86(2), 173-184.

Duran, E., Ballone-Duran, L., Haney, J., \& Beltyukova, S. (2009). The impact of a professional development program integrating informal science education on early childhood teachers' self-efficacy and beliefs about inquiry-based science teaching. Journal of Elementary Science Education, 21, 4, 53-70. 
Elliot, M. E., Issacs, M. L., \& Chugani, C. D. (2010). Promoting self-efficacy in early career teachers: A principal's guide for differentiated mentoring and supervision. Florida Journal of Educational Administration and Policy, 4, 131-146.

Field, A. (2009). Discovering Statistics using SPSS ( $3^{\text {rd }}$ ed). Thousand Oaks, CA: Sage Publications.

Furlong, M., Morrison, G., \& Jimerson, S. (2004). Externalizing Behaviors of Aggression and Violence and the School Context. In R. B. Rutherford, M. M. Quinn, \& S.R. Mathur (Eds.) Handbook of Research in Emotional and Behavioral Disorders (pp.243-262). New York, NY: Guilford Press.

Gall, M. D., Gall, J. P., \& Borg, W. R. (2007). Educational Research: An Introduction $\left(8^{\text {th }} e d\right)$. Boston, MA: Pearson.

Goddard, R. D., \& Goddard, Y. L. (2001). A multilevel analysis of the relationship between teacher and collective efficacy in urban schools. Teaching and Teacher Education, 17(7), 807-818.

Gresham, M. F., \& Kern, L. (2004). Internalizing Behavior Problems in Children and Adolescents. In R. B. Rutherford, M. M. Quinn, \& S. R. Mathur (Eds.) Handbook of Research in Emotional and Behavioral Disorders (pp. 262-282). New York, NY: Guilford Press.

Gurvitch, R., \& Metzler, M. W. (2009). The effects of laboratory-based and field- based practicum experience on pre-service teachers' self efficacy. Teaching and Teacher Education, 25, 437-443.

Hong, J. Y. (2010). Preservice and beginning teachers' professional identity and its relation to dropping out of the profession. Teaching and Teacher Education, 26,(8), 1530-1543. 
Heneman, H. G., III, Kimball, S., \& Milanowski, A. (2006, October). The teacher sense of efficacy scale: Validation evidence and behavioral prediction (WCER Working Paper No. 2006-7). Madison: University of Wisconsin-Madison, Wisconsin Center for Education Research. Retrieved from http://www.wcer.wisc.edu/publications/workingPapers/papers.php.

Hughes, J. N., Barker, D., Kemenoff, S., \& Hart, M. (1993). Problem ownership, causal attributions, and self-efficacy as predictors of teachers' referral decisions. Journal of Educational \& Psychological Consultation, 4(4), 369-384.

Jeon, H., \& Peterson, C. A. (2003). Preservice teachers' attitudes toward inclusion: Early childhood education and elementary education programs. Journal of Early Childhood Teacher Education, 24, 171-179. doi: 10.1080/1090102030240306

Jobe, D., James, R. O., \& Brissie, J. (1996). Teachers' attitudes toward inclusion of students with disabilities into regular classrooms. Education, 117, 148-153.

Kamens, M. W., Loprete, S. J., \& Slostad, F. A. (2000). Classroom teachers' perceptions about inclusion and preservice teacher education. Teaching Education, 11,147158. doi: $10.1080 / 713698971$

Kauffman, J. M. (1997). Characteristics of Emotional and Behavioral Disorders of Children and Youth ( $\left.6^{\text {th }} e d\right)$. Upper Saddle River, NJ: Prentice-Hall Inc.

Klassen, R. M. (2010). Teacher stress: The mediating role of collective efficacy beliefs. The Journal of Educational Research, 103, 342350.doi:10.1080/00220670903383069

Klassen, R. M., \& Chiu, M. (2010). Effects on teachers' self-efficacy and job satisfaction: Teacher gender, years of experience, and job stress. Journal of Educational Psychology, 102, 741-756 doi: 10.1037/a0019237 
Kurz, T. B., \& Knight, S. L. (2004). An exploration of the relationship among teacher efficacy, collective teacher efficacy, and goal consensus. Learning Environments Research, 7, 111-128.

Lane, K., Wehby, J., \& Barton-Arwood, S. (2005). Students With and At Risk for Emotional and Behavioral Disorders: Meeting Their Social and Academic Needs. Preventing School Failure, 49, 6-9.

Lanier, N. J., \& Lanier, W. L. (1996). The effects of experience on teachers' attitudes toward incorporating special students into the regular classroom. Education, 117, 234-240.

Larrivee, B., \& Cook, L. (1979). Mainstreaming: A study of the variables affecting teacher attitude. Journal of Special Education, 13, 315-324. doi:

$10.1177 / 002246697901300310$

Lee, V. E., Dedrick, R. F., \& Smith, J. B. (1991). The effect of the social organization of schools on teachers' efficacy and satisfaction. Sociology of Education, 64, (3), 190208.

Main, S., \& Hammond, L. (2008). Best Practice or Most Practiced? Pre-service Teachers' Beliefs about Effective Behaviour Management Strategies and Reported Self efficacy. Australian Journal of Teacher Education, 33, 28-39.

Manning, M., Bullock, L., \& Gable, R. (2009). Personnel Preparation in the Area of Emotional and Behavioral Disorders: A Reexamination Based on Teacher Perceptions. Preventing School Failure, 53, 219-226.

Maslach, C., Schaufeli, W. B., \& Leiter, M. P. (2001). Job burnout. Annual Review of Psychology, 52, 397-422. 
McDonnough, J. T., \& Matkins, J. J. (2010). The role of field experience in elementary preservice teachers' self- efficacy and ability to connect research to practice. School Science and Mathematics, 110(1), 13-23.

Mock, D. R., \& Kauffman, J. M. (2002). Preparing teachers for full inclusion: Is it possible? The Teacher Educator, 37, 202- 215. doi: 10.1080/08878730209555294

Monahan, R. G., Marino, S.B., \& Miller, R. (1996). Teacher attitudes toward inclusion: Implications for teacher education in schools 2000. Education, 117, 316-320.

National Association of School Psychologists (2005). Position Statement on Students with Emotional and Behavioral Disorders. Retrieved from http://www.nasponline.org/about nasp/pospaper sebd.aspx

Newcomer, P. L. (2003). Understanding and teaching emotionally disturbed children and adolescents. ( $3^{\text {rd }}$ ed). Austin, TX: Pro Ed.

Pianta, R. P. (1999). Enhancing relationships between children and teachers. Washington, DC: American Psychological Association.

Pierangelo, R., \& Giuliani, G. (2008). Classroom Management for Students with Emotional and Behavioral Disorders. California: Corwin Press.

Plourde, L. (2002). The influence of student teaching on preservice elementary teachers' science self efficacy and outcome expectancy beliefs. Journal of Instructional Psychology, 29(4), 245-253.

Rapport, M. D., Denney, C. B., Chung, K., \& Hustace, K. (2001). Internalizing Behavior Problems and Scholastic Achievement in Children: Cognitive and Behavioral Pathways as Mediators of Outcome. Journal of Clinical Child Psychology, 30, $536-551$. 
Raudenbush, S. W., Rowan, B., \& Cheong, Y. F. (1992). Contextual effects on the self perceived efficacy of high school teachers. Sociology and Education, 65, 150-167.

Rizza, M. G., \& Morrison, W. F. (2003). Uncovering stereotypes and identifying characteristics of gifted students and students with emotional/behavioral disabilities. Roeper Review, 25, 73-77.

Schwarzer, R., \& Hallum, S. (2008). Perceived teacher self-efficacy as a predictor of job stress and burnout: Mediation analyses. Applied Psychology: An International Review, 57, 152-171. doi:10.1111/j.1464-0597.2008.00359.x

Shippen, M. E., Crites, S. A., Houchins, D.E., Ramsey, M. L., \& Simon, M. (2005). Preservice teachers' perceptions of including students with disabilities. Teacher Education and Special Education, 28(2), 14-21.

Singh, K., \& Billingsley, B. S. (1996). Intent to stay in teaching. Remedial \& Special Education, 17, 37-48.

Skaalvik, E. M., \& Skaalvik, S. (2007). Dimensions of teacher self-efficacy and relations with strain factors, perceived collective teacher efficacy, and teacher burnout. Journal of Educational Psychology, 99, 611-625. doi: 10.1037/0022-0663.99.3.611

Soles, T., Bloom, E., Heath, N., \& Karagiannakis, A. (2008). An exploration of teachers' current perceptions of children with emotional and behavioural difficulties. Emotional \& Behavioural Difficulties, 13, 275-290.

Soodak, L. C., \& Podell, D. M. (1994). Teachers' thinking about difficult-to-teach students. Journal of Educational Research, 88(1), 44-51.

Sutherland, K., Lewis-Palmer, T., Stichter, J., \& Morgan, P. (2008). Examining the Influence of Teacher Behavior and Classroom Context on the Behavioral and 
Academic Outcomes for Students with Emotional or Behavioral Disorders. Journal of Special Education, 41(4), 223-233. doi: 10.1177/0022466907310372.

Swackhamer, L, E., Koellner, K., Basile, C., \& Kimbrough, D. (2009). Increasing the self efficacy of inservice teachers through content knowledge. Teacher Education Quarterly, 36, 63-78.

Tait, M. (2008). Resilience as a contributor to novice teacher success, commitment, and retention. Teacher Education Quarterly, 35, 57-75.

Taylor, D. L., \& Tashakkori, A. (1995). Decision participation and school climate as predictors of job satisfaction and teachers' sense of efficacy. The Journal of Experimental Education, 63(3), 217-230.

Tschannen-Moran, M., \& McMaster, P. (2009). Sources of self-Efficacy: Four professional development formats and their relationship to self-efficacy and implementation of a new teaching strategy. The Elementary School Journal, 110(2), $228-245$.

Tschannen-Moran, M., \& Woolfolk-Hoy, A. (2001). Teacher efficacy: Capturing an elusive construct. Teaching and Teacher Education, 17, 783-805.

Tschannen-Moran, M., \& Woolfolk-Hoy, A. (2007). The differential antecedents of selfefficacy beliefs of novice and experienced teachers. Teaching and Teacher Education, 23, 944-956.

Turner, N. D. (1995). Two approaches to the field experience and the effects on attitudes of preservice teachers towards inclusion. The Teacher Educator, 31, 96 -105. doi: 10.1080/08878739509555102 
U.S. Department of Education, National Center for Education Statistics (2010). Digest of Education Statistics, 2009 (NCES 2010-013), Chapter 2. Retrieved from http://nces.ed.gov/fastfacts/display.asp?id=59

U.S. Department of Education, National Center for Education Statistics (2010). Projection of Education Statistics to 2019 (NCES 2011-017), Section 3. Retrieved from http://nces.ed.gov/programs/projections/projections2019/sec3b.asp

U.S. Department of Education, National Center for Education Statistics (2010). Teacher Attrition and Mobility: Results from the 2008-09 Teacher Follow-up Survey (NCES 2010-013), Chapter 2. Retrieved from http://nces.ed.gov/pubsearch/pubsinfo.asp?pubid=2010353

U.S. Department of Education, Special education \& Rehabilitative services (2010). Retrieved from http://www2.ed.gov/policy/speced/leg/idea/history30.html

Viel-Rumal, K., Houchins, D., Jolivette', K., \& Benson, G. (2010). Efficacy beliefs of special educators: The relationships among collective efficacy, teacher selfefficacy, and job satisfaction. Teacher Education and Special Education 33, 225 233. doi: 10.117710888406409360129

Whitley, J. (2010). Modeling the influence of teacher characteristics on student achievement for Canadian students with and without learning disabilities. International Journal of Special Education, 25, 88-97.

Woolfolk, A. E., \& Hoy, W. K. (1990). Prospective teachers' sense of efficacy and beliefs about control. Journal of Educational Psychology, 82(1), 81-91.

Woolfolk, A. E., Rosoff, B., \& Hoy, W. K. (1990). Teachers' sense of efficacy and their beliefs about managing students. Teaching and Teacher Education, 6(2), 137-148. 
Woolfson, L. M., \& Brady, K. (2009). An investigation of factors impacting on mainstream teachers' beliefs about teaching students with learning difficulties. Educational Psychology, 29, 221 -238. doi: 10.1080/01443410802708895

Yoon, J. S. (2002). Teacher characteristics as predictors of teacher-student relationships: stress, negative affect, and self-efficacy. Social Behavior \& Personality: An International Journal, 30, 485-493.

Yost, D. S. (2006). Reflection and self-efficacy: Enhancing the retention of qualified teachers from a teacher education perspective. Teacher Education Quarterly, 33, 59-76.

Zaccaro, S. J., Blair, V., Peterson, C., \& Zazanis, M. (1995). Collective efficacy: Selfefficacy, adaptation, and adjustment: Theory, research, and application. In J. E. Maddux (Ed). Self-efficacy, adaptation, and adjustment: Theory, research, and application, The Plenum series in social/clinical psychology (pp. 305-328). New York, NY: Plenum Press. 
APPENDIX A CONSENT FORM 


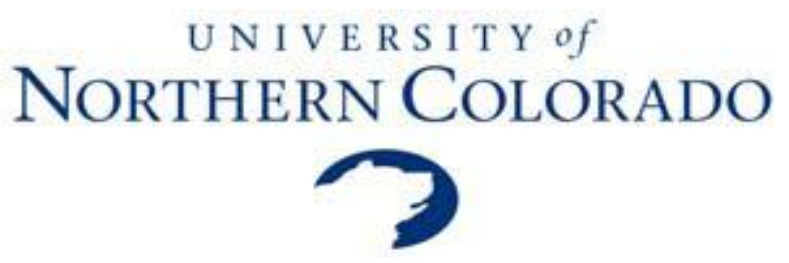

\section{Consent Form for Human Participants in Research University of Northern Colorado}

Project Title: Preservice Teachers' Self Efficacy and Knowledge of Emotional and Behavioral Disorders

Researcher: Shani Shillingford

Advisor: Nancy J. Karlin, Ph.D

Phone: 318-573-6665

Phone: 970-351-2717

Email: shil2375@bears.unco.edu

Email: nancy.karlin@unco.edu

The purpose of this study is to examine what factors influence preservice teachers' self efficacy and ability to effectively work with students with Emotional and Behavioral Disorders (EBD). There are approximately 200 general and special education students at the university who will be invited to participate in this study. This research will compare teachers' knowledge of EBD and self efficacy across different teacher education programs. This study will provide useful information to assist in the further development of effective teacher education programs, to ensure that new teachers are fully equipped to work with the diverse populations in their classrooms.

As a participant, you will first be asked to complete Section I, which asks for your opinions about 24 statements. You will then answer section II, which asks you to answer 15 questions based on your knowledge of EBD, and finally you will complete Section III which asks for demographic information such as age, program of study, and experience with EBD. The entire survey should take about 30 minutes to complete. After you complete the survey, place it in the box provided in the room. There are no foreseeable risks to participants.

At the end of the research, you are free to view the findings. Contact the researcher using the contact information above. Please understand that the findings of the research may be published in a scientific journal or presented at professional meetings. At no time will any personal identifiers be used when disseminating the research findings. All measures will be taken to protect your identity. Results of the study will be presented in group form only (e.g., averages). The data collected will be held in a locked file cabinet in my academic advisor's office and only the researcher and advisor will have access to data.

Participation is voluntary. You may decide not to participate in this study and if you begin participation you may still decide to stop and withdraw at any time. Your decision will be respected and will not result in loss of benefits to which you are otherwise entitled. Having read the above and having had an opportunity to ask any questions please complete the questionnaire if you would like to participate in this research. By completing the questionnaire, you will give us permission for your participation. You may keep this form for future reference. If you have any concerns about your selection or treatment as a research participant, please contact the Office of Sponsored Programs, 25 Kepner Hall, University of Northern Colorado, Greeley, CO 80639; 970$351-2161$ 
APPENDIX B

KNOWLEDGE OF EBD QUESTIONNAIRE 


\section{Knowledge of Emotional and Behavioral Disorders (EBD)}

Below are short vignettes describing different children and various behavior patterns. For each vignette you are either given several possible explanations for the child's behavior or several alternatives for managing the behavior. Based on your experience or knowledge of EBD, circle the most appropriate response. Please answer each question.

1. John is usually a well behaved child, but in the past three weeks, John's behavior has changed. He is constantly getting into fights with his peers, is being rude to the teacher, and fails to complete his assignments. His mother also reports having difficulty getting John to do his chores, since his parents' separation 3 weeks ago. What is the best explanation for John's change in behavior?
a. Anger
b. Conduct problems
c. Depression
d. Influence of peers

2. Six weeks after his grandmother's death, Sam finds it difficult to concentrate in school and his grades have dropped. His teacher noticed that Sam sits alone on the playground and sometimes skips lunch. The best explanation for Sam's behavior is:
a. Attention seeking
b. Depression
c. Grief
d. Sadness

3. The teacher noticed Jane on the first day of the new school year clinging to her mother and crying because she did not want to go to school. Two months later, Jane is still exhibiting these behaviors every morning. Also, she is constantly sleeping in class and is unable to concentrate on her school work. Her mother reported that Jane has nightmares and thus is not getting enough sleep at nights. Jane complains constantly of stomach-aches and headaches. Her mother believes it's because of the nightmares. The most appropriate explanation for Jane's behavior is:
a. Anxiety
b. Depression
c. Dislike for school
d. Nightmares

4. John, a middle school student, is constantly initiating fights with his peers. He is also known to be cruel to the stray dogs outside the school. John is doing poorly academically and is often truant from school. What is the best explanation for John's behavior?
a. Anger
b. Bullying
c. Conduct problems
d. Mean spirited

5. During the lesson, Sam who is known to have attention problems begins singing his favorite song out loud and disrupts the class. The best way to diffuse this problem is to
a. Begin discussing Sam's favorite topic
b. Punish Sam for his behavior
c. Quietly remove Sam from the classroom
d. Yell at Sam to quiet down 
6. Amy is a very anxious child. She has difficulty completing her tasks and spends her time distracting the other students. What is the best way to help Amy complete her assignments?

a. Break the assignments into smaller tasks for Amy

b. Deduct points from Amy's grade for each incomplete assignment

c. Give Amy extra time to complete the assignment

d. Place Amy away from other students to keep her focused

7. John is constantly getting out of his seat and wanders around the room. He tries to engage other students in conversation and disrupts the classroom. What is the best approach for handling John's behavior?
a. Direct John to return to his seat
b. Give John an activity to do like erasing the board
c. Ignore John's behavior
d. Remove John from the classroom

\section{Please circle whether the following statements are either True or False.}

8. Antidepressants are not administered to children as part of treatment for depression.
a. True
b. False

9. Anxious children may also be quiet, compliant, and eager to please.
a. True
b. False

10. Children and adolescents self-mutilate simply as a form of rebellion, to reject their parents' values, or to be accepted.
a. True
b. False

11. Adolescents who exhibit conduct problems are only going through their puberty phase and will outgrow it by adulthood.
a. True
b. False

12. If a child who is diagnosed with Attention Deficit Hyperactivity Disorder (ADHD) is prescribed medication, an educational intervention is not necessary.
a. True
b. False

13. Children with ADHD cannot sit still long enough to pay attention.
a. True
b. False

14. A child who is not overactive, but fails to pay attention, may have ADHD.
a. True
b. False

15. Oppositional behavior is often a normal part of development for two to three year olds and early adolescents.
a. True
b. False 
APPENDIX C

DEMOGRAPHIC INFORMATION QUESTIONNAIRE 


\section{Knowledge of Emotional and Behavioral Disorders (EBD)}

Demographic Questions

This section of the survey asks for demographic information and information related to your program of study and experience with $\mathrm{EBD}$. Please put a check next to the appropriate response and where indicated please fill the blank with the specific response. Please answer all questions.

Gender:

Male

Female

Race: Please check only one from the list below:

White

Asian

Hispanic/Latino

Other (specify)

Classification:

Freshman

Junior
Age:

Black or African American

American Indian

Mixed Race (Specify)

Program of study:

Please check all that apply from the list below:

Early Childhood (Birth-Grade 3)

Secondary (Grades 7-12)

Music (K- Grade 12)

Bilingual Bicultural Education

Special Education

Master's of teaching in Elementary Education

Senior Graduate

Have you completed practicum or field experience? Yes

No

If yes, please indicate type of classroom:

Inclusive classroom

Elementary (K- Grade 6)

Art (K- Grade12)

Physical Education (K-Grade12)

English as a Second Language

Post Baccalaureate

Other (Specify)

Duration of Placement

Special Education Classroom

Please indicate whether any of the students in the classroom were diagnosed with EBD

Yes

No

I've worked with or known a child diagnosed with an Emotional or Behavioral Disorder:

Yes__ No

If yes, please indicate the type of EBD

Please indicate the estimated number of children known or worked with

Please indicate your relationship with the child known or worked with (check all that apply):

Daughter or Son

Sibling

Relative

Student

Other (Specify)

Have you taken any special education courses or coursework related to EBD?

Yes No

If yes, check all that apply from the list below:

Educational Psychology

Special Education Courses

Educational Technology

Other (Specify)

Foundations of Education 
APPENDIX D

DEBRIEFING FORM 


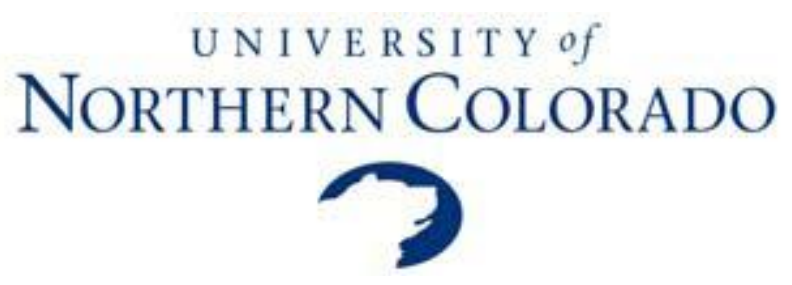

\section{Teacher Self Efficacy and Knowledge of Emotional and Behavioral Disorders Debriefing Form}

\section{Purpose}

The purpose of this research was to examine what factors influence preservice teachers' self efficacy and ability to effectively work with students with Emotional and Behavioral Disorders (EBD).This information will prove useful to teacher education program coordinators to help in further developing effective programs that equip new teachers with the tools needed for working with the diverse population in their classrooms.

\section{Methodology}

For the study, you were asked to complete a demographic data form, the Knowledge of EBD Questionnaire and the Teacher Sense of Self Efficacy Scale (TSES). Your response on the Knowledge of EBD questionnaire and TSES will be compared to information provided on the demographic data form.

\section{Confidentiality}

The results of the study will be presented in group format such as averages and percentages. There will be no identifying markers. These results may be published in journals or be presented at professional meetings. Every effort will be made to ensure your identity will not be revealed.

\section{Contact Information}

Should you have any questions or concerns about the study feel free to contact Shani Shillingford at shi12375@ bears.unco.edu. or Nancy Karlin at nancy.karlin@ unco.edu ; (970) 351-2717.

If you are interested in learning more about the study or receiving a copy of the report, don't hesitate to contact the researcher at the address above.

\section{Additional Resources}

For more information on Teacher Self Efficacy and Knowledge of Emotional and Behavioral Disorders see below:

Kauffman, J.M. (1997). Characteristics of Emotional and Behavioral Disorders of Children and Youth $\left(6^{\text {th }} e d\right)$. Upper Saddle River, NJ: Prentice-Hall Inc.

Manning, M., Bullock, L., \& Gable, R. (2009). Personnel Preparation in the Area of Emotional and Behavioral Disorders: A Reexamination Based on Teacher Perceptions. Preventing School Failure, 53, 219-226.

Thank you for your help and participation in this study. 
APPENDIX E

INSTITUTIONAL REVIEW BOARD APPLICATION AND APPROVAL 


\section{Research Involving Human Participants Coversheet for UNC IRB Application}

UNIVERSITY of

NORTHERN COLORADO

Project Title: Preservice Teachers' Self Efficacy and Knowledge of Emotional and Behavioral Disorders

\section{Contact Information (reviewers will communicate via e-mail)}

Lead Investigator: Shani Shillingford

phone: 318-573-6665

School: University of Northern Colorado UNC e-mail: shil2375@bears.unco.edu

Research Advisor: Nancy Karlin UNC e-mail: nancy.karlin@unco.edu

(required for students)

\section{CERTIFICATION OF LEAD INVESTIGATOR}

I certify that this application accurately reflects the proposed research and that I and all researchers who will have contact with the participants or access to the data have reviewed this application and the Guidelines of the UNC IRB and will comply with the letter and spirit of these policies. I understand that any changes in procedure which affect participants must be submitted to the IRB (using the Request for Change in Protocol Form) for written approval prior to their implementation. I further understand that any adverse events and significant changes in risk for participants must be immediately reported in writing to the UNC IRB.

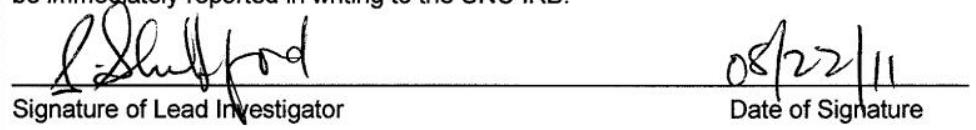

CERTIFICATION OF RESEARCH ADVISOR (If Lead Investigator is a Student)

I certify that I have thoroughly reviewed this application; confirm its accuracy, and accept responsibility for monitoring the conduct of this research, the maintenance of any consent documents as required by the IRB, and, in the case of

expefited reviews, the continuation review of this project in approximately one year.

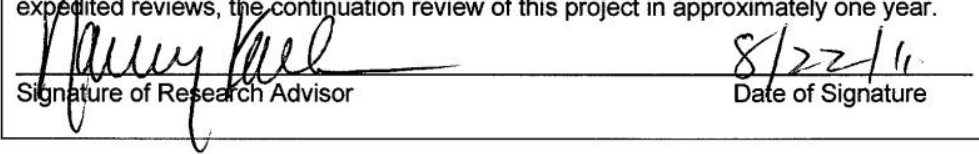

Summary Information (to be completed by Lead Investigator)

Review Category: $\square$ Exempt (2-3 weeks) $\square$ Expedited (3-4 weeks) $\square$ Full-Board (4-6 weeks)

Research participants will be: (e.g., adults, elderly, children healthy, unhealthy, etc.)

Type of data collected will be:

(e.g., survey responses, interviews

blood samples, existing data, etc.)

Location of data collection: Adults

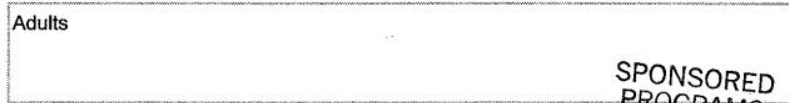

Survey Responses

AUG 242011

Is standard consent documentation used? $\square$ YES $\square$ NO If NO, must be addressed within application.

Is permission required (e.g., school district)? $\square$ YES $\square$ NO If YES, must include letter (this is not consent).

Is this a funded research project?

YES $\checkmark$ NO If YES, must provide source within application.

Submit the original and one copy of the cover page, narrative, and all attachments to OSP, Kepner Hall \#25, Attn: Sherry May 


\section{UNIVERSITY of \\ NORTHERN COLORADO \\ Institutional Review Board (IRB)}

August 25, 2011

TO:

Maria Lahman

Applied Statistics and Research Methods

FROM: $\quad$ The Office of Sponsored Programs

RE: $\quad$ Exempt Review of Preservice Teachers' Self Efficacy and Knowledge of Emotional and Behavioral Disorders, submitted by Shani Shillingford (Research Advisor: Nancy Karlin)

The above proposal is being submitted to you for exemption review. When approved, return the proposal to Sherry May in the Office of Sponsored Programs.

I recommend approval.

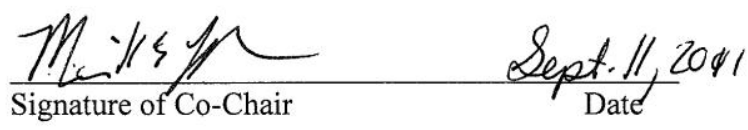

The above referenced prospectus has been reviewed for compliance with HHS guidelines for ethical principles in human subjects research. The decision of the Institutional Review Board is that the project is exempt from further review.

IT IS THE ADVISOR'S RESPONSIBILITY TO NOTIFY THE STUDENT OF THIS STATUS.

Comments: 